\title{
HUMANITARIAN EFFECTIVENESS IN COMPLEX EMERGENCIES: \\ SOUTH SUDAN AND DARFUR
}

\author{
Master of International Relations Thesis
}

Victoria University of Wellington

Pavlina Jirouskova 


\section{ACKNOWLEGMENTS}

I would like to deeply thank my supervisors Dr Kate Schick and AProf Ben Thirkell-White for their kind support and guidance. They have certainly made my life a lot easier and I cannot thank them enough.

I would also like to thank my friends and family who have believed in me and supported me throughout this project. I would like to dedicate this thesis to my father who recently passed away. I know he would be proud of me for this achievement despite all the obstacles and roadblocks life has brought me in the past year. 


\section{CONTENTS}

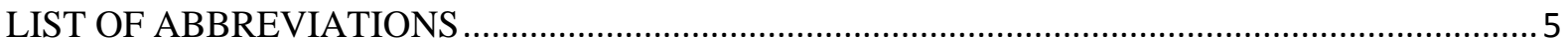

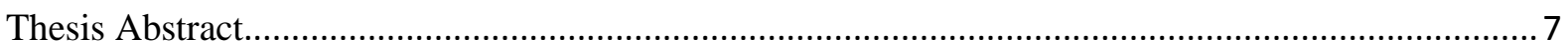

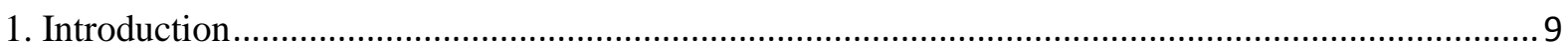

2. New Humanitarianism and Humanitarian Effectiveness ............................................................. 15

3. Humanitarian Effectiveness during Operation Lifeline Sudan .........................................................24

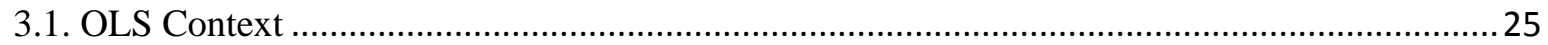

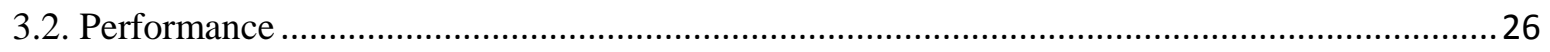

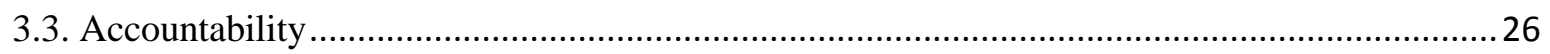

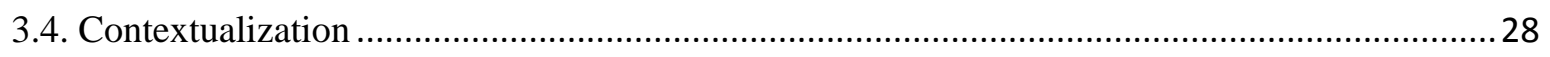

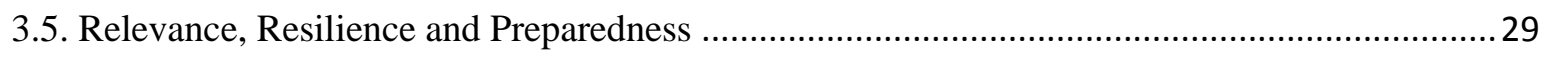

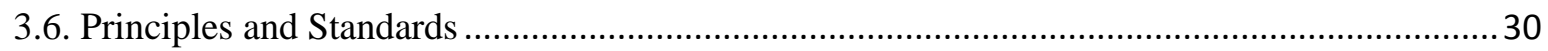

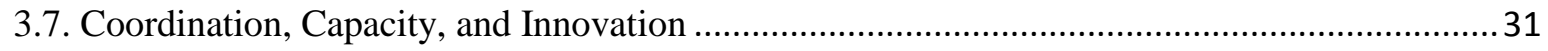

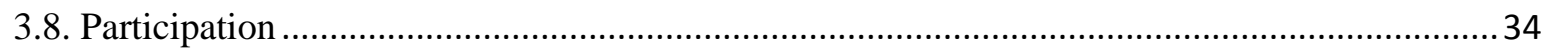

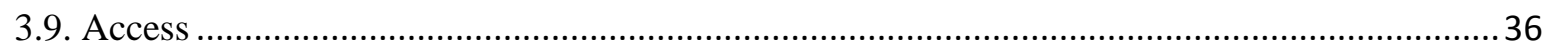

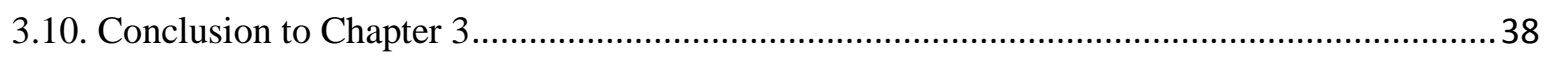

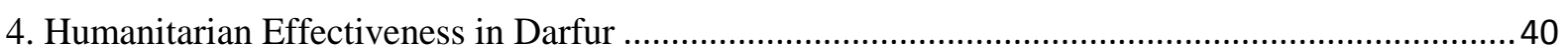

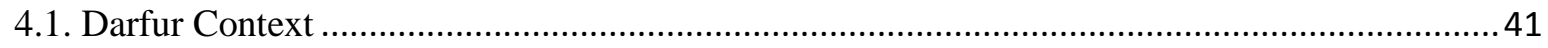

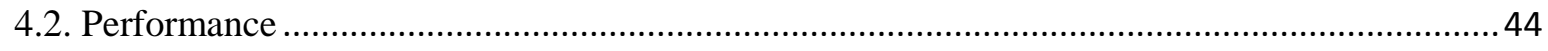

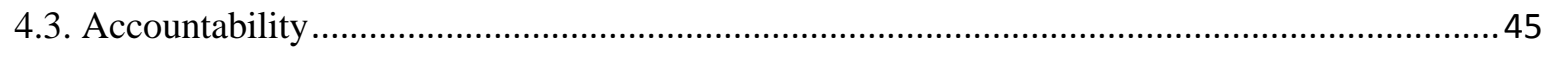

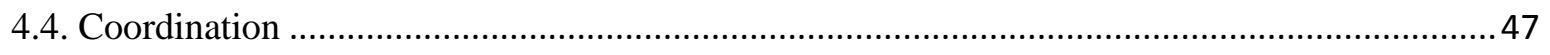

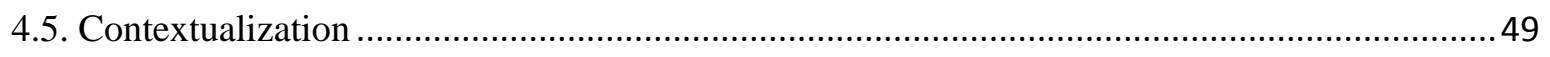

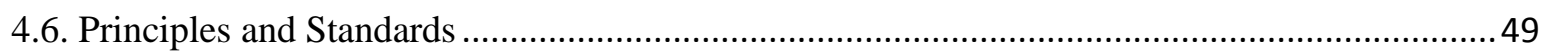

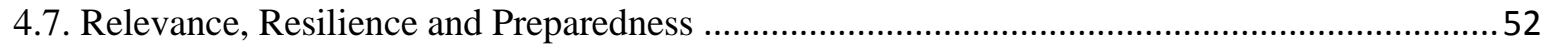

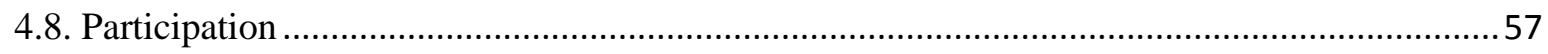

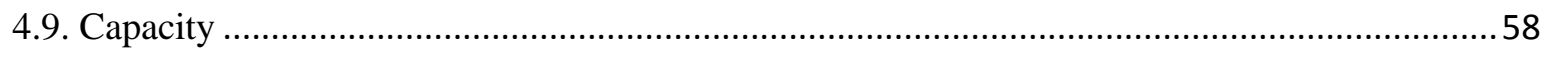

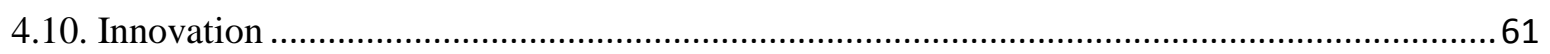




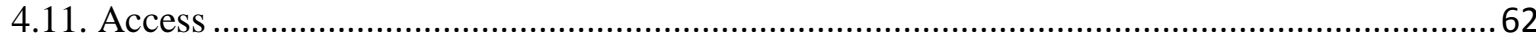

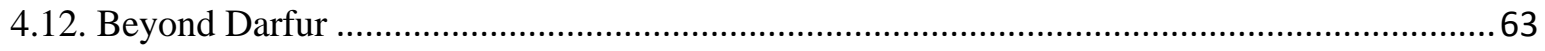

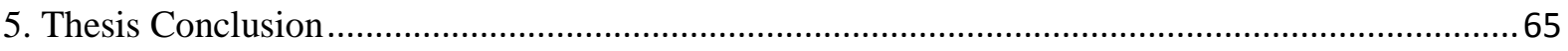

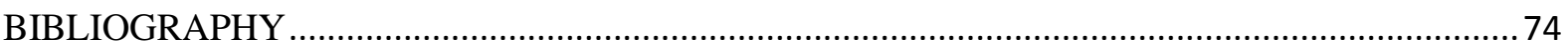

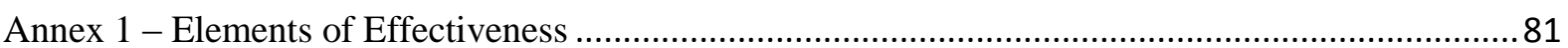




\section{LIST OF ABBREVIATIONS}

\begin{tabular}{|c|c|}
\hline AMIS & African Union Mission in Sudan \\
\hline CAP & Consolidated Appeal Process \\
\hline CPA & Comprehensive Peace Agreement \\
\hline $\mathrm{CHF}$ & Common Humanitarian Fund \\
\hline CERF & Central Emergency Response Fund \\
\hline $\mathrm{ECHO}$ & Humanitarian Aid and Civil Protection (European Union) \\
\hline EU & European Union \\
\hline GoS & Government of Sudan \\
\hline GoSS & Government of South Sudan \\
\hline HAP & Humanitarian Accountability Partnership \\
\hline ICRC & International Committee of the Red Cross \\
\hline IDP & Internationally displaced person \\
\hline IFRC & International Federation of Red Cross and Red Crescent Societies \\
\hline IOM & International Organisation for Migration \\
\hline JEM & Justice and Equality Movement \\
\hline MSF & Médecins Sans Frontières (Doctors Without Borders) \\
\hline NGO & Nongovernmental organisation \\
\hline OCHA & Office for the Coordination of Humanitarian Affairs (United Nations) \\
\hline OECD & Organisation for Economic Development \\
\hline
\end{tabular}

OECD/DAC Development Assistance Committee of the Organisation for Economic Development

OLS Operation Lifeline Sudan

R2P Responsibility to protect

SPLA Sudan People's Liberation Army 
SRRA Sudan Relief and Rehabilitation Commission

UN United Nations

UNAMID African Union/United Nations Hybrid Mission in Darfur

UNHCR United Nations High Commissioner for Refugees

UNICEF United Nations Children's Fund

UNMIS United Nations Mission in Sudan

UNMISS United Nations Mission in South Sudan

UN GA United Nations General Assembly

UN SC United Nations Security Council

WFP World Food Programme

WHS World Humanitarian Summit 


\section{Thesis Abstract}

My Master's Thesis explores the extent to which the international community has established processes of evaluation and learning that are improving humanitarian responses to complex humanitarian emergencies over time. It does so by reviewing a range of existing evaluations of successive crises in the former Sudan, with particular emphasis on Operation Lifeline Sudan (OLS) and Darfur. I assert that by addressing the shortcomings of past humanitarian operations and learning from them, the international community can improve the effectiveness of future humanitarian responses. OLS, which was the first multilateral humanitarian operation after the end of the Cold War and which is perceived as one of the biggest failures in humanitarian aid history, will be used as a starting point. Consequently, I used the case of Darfur in order to answer the following research questions: How has humanitarian effectiveness evolved in the former Sudan since the launch of OLS? Have lessons been learned from the failures of OLS? To answer these questions, I applied the UN OCHA-proposed Elements of Effectiveness as a framework, namely: performance, accountability, coordination, contextualization, principles and standards, relevance, participation, capacity, resilience and preparedness, innovation, and access.

The thesis is divided into three main parts. The first part (chapter 2) explains how humanitarian aid has evolved after the end of the Cold War in regard to complex emergencies, and why the international community has felt the need for evaluating and improving humanitarian effectiveness. Chapters three and four critically analyse humanitarian effectiveness in the former Sudan, during OLS and in Darfur, respectively, in order to demonstrate how ineffective humanitarian aid has been and how little has changed in the international response, despite the fact that the former Sudan has been one of the largest recipients of humanitarian aid since the end of the Cold War.

I argue that humanitarian aid has generally been seen as a failure since the end of the Cold War, and that evaluating humanitarian effectiveness is necessary for the improvement of humanitarian aid. On the other hand, complex emergencies are inherently political and require addressing their underlying socio-economic causes. Therefore, humanitarian aid cannot be solely blamed for the overall failures of international interventions, as it only exists alongside of crises and it is limited to saving lives, alleviating suffering of affected populations, and maintaining their human dignity. International actors mostly failed to address political problems of crises in the aftermath of the Cold War and humanitarian aid 
was used as the only response. When the crisis in Darfur broke out, the international community had more than ten years of experience in responding to complex emergencies. Yet, it again failed to respond effectively and repeated many of the mistakes of OLS. Major weaknesses of both operations were, apart from lacking political response, also problems associated with accessibility and lacking coordination and cooperation between humanitarian agencies.

Although some improvements have been finally made in terms of humanitarian effectiveness in the past decade, there are still major problems in the humanitarian sector, such as insufficient funding mechanisms and inability of the UN to resolve prolonged crises on a political level. Furthermore, humanitarian aid is still characterised by a lack of data. Therefore, I assert that it is important to develop better standards for humanitarian response based on reflections on past operations. The Elements of Effectiveness give the impression of a useful starting point for developing such standards. Unified standards for monitoring and evaluation of humanitarian operations on an on-going basis will enable the international community to learn from past mistakes and to effectively fulfil the primary objectives of humanitarian aid. 


\section{Introduction}

This thesis explores the extent to which the international community has established processes of evaluation and learning that are improving humanitarian responses to complex humanitarian emergencies over time. It does so by reviewing a range of existing evaluations of successive crises in the former Sudan, with particular emphasis on Operation Lifeline Sudan (OLS) and Darfur. Humanitarian aid experienced a major transformation after the end of the Cold War due to the rise of complex humanitarian emergencies, caused by increased incidence of intrastate conflicts. At the same time, the end of the Cold War enabled humanitarian actors better access to affected populations due to abandoning the notion of absolute sovereignty. Humanitarian operations in the aftermath of the Cold War are, however, characterized by adhocracy and periodic repetition of the same mistakes. Multilateral humanitarian operations have been largely ineffective, particularly in fragile environments, such as the former Sudan. Even though the international community has acknowledged that humanitarian aid has not been very effective and has been trying to find ways to improve it, only recently, has it recognised the need to evaluate humanitarian aid and learn from previous mistakes in order to improve overall humanitarian effectiveness.

Addressing humanitarian effectiveness is undoubtedly a positive improvement for humanitarian aid. Its growing importance is visible from the United Nations (UN) Office for Coordination of Humanitarian Affairs (OCHA) agenda, related to the upcoming World Humanitarian Summit, which perceives humanitarian effectiveness as the one of the top priorities of the humanitarian sector. The cases of OLS and Darfur are ideal for demonstrating shortcomings of multilateral humanitarian operations. The former Sudan experienced one of the first humanitarian operations after the end of the Cold War and it has been one of the largest recipients of humanitarian aid ever since. Although the crises unfolded in different parts of the former Sudan and the Darfur crisis broke out more than ten years after the launch of OLS, both emergencies involved the same actors and they were characterised by the same mistakes of humanitarian agencies. If the international community would have learned from the failures of OLS, it possibly could have prevented many of the same failures in Darfur. I assert that by addressing the shortcomings of past humanitarian operations and learning from them, the international community can improve the effectiveness of future humanitarian responses. 
The international community provides humanitarian aid to populations who have been affected by natural or man-made disasters. Contemporary crises, often caused by the combination of natural and man-made disasters, are called complex emergencies. The development of complex emergencies relates to the shift from interstate to intrastate conflict after the end of the Cold War. Some argue that in new wars, civilians are directly affected by conflicts as opposed to in traditional warfare where civilian casualties were minimal. However, Fiona Terry suggests that the complexity of contemporary crises is caused by the number and variety of responses and actors involved in them (Terry, 2002, p. 15). While natural disasters usually cause instant loss of life and immediate displacement of affected populations, complex emergencies have mostly a slower impact. However, if the humanitarian community fails to respond in a timely and effective manner, a complex emergency can have dire consequences for the civilian population. The number of complex emergencies has rapidly increased over the last few decades. Consequently, there has been a sharp increase in the numbers of deaths resulting from intrastate conflicts and the numbers of people affected by them (Riddell, 2007, p. 313). Contemporary crises cause widespread suffering and massive loss of life. They are characterized by violence, insecurity, disruption of services and infrastructure, and loss of livelihoods. Populations affected by complex emergencies are not able to fulfil their own basic needs, such as food, water, healthcare, shelter, and sanitation (Riddell, 2007, p. 311). They are often forced to leave their homes not only to flee the violence, but also to search for water and food.

Therefore, modern conflicts often result in widespread displacement. During the Second World War and during the Cold War, populations displaced by interstate conflicts sought refuge in neighbouring countries or abroad. This exodus has, however, changed after the end of the Cold War. In the last few decades, there has been a sharp increase in the numbers of internally displaced people (IDPs) due to the nature of contemporary warfare (Riddell, 2007, p. 314). Another reason for the increase of IDP numbers is that after the end of the Cold War the international community has refrained from the notion of absolute sovereignty. Affected populations have become accessible within their country of origin which consequently has led to major changes in the humanitarian aid sector. Furthermore, due to the protracted nature of contemporary conflicts, neighbouring countries are no longer as welcoming towards refugees since hosting large numbers of refugees for longer periods of time puts a strain on the host community (Duffield, 1997, p. 530). 
The former Sudan, divided into the Republic of Sudan in the North and Republic of South Sudan in the South since 2011, has had one of the largest internally displaced populations in the world. It has also been one of the largest recipients of foreign assistance in the last 25 years, prompted by protracted crises. These crises have been caused by long-standing conflict between the North and the South, tensions between the government and various opposition groups, and inter-ethnic fighting, in combination with natural disasters, namely droughts and floods. Recurring conflict in the former Sudan has caused on-going insecurity, loss of life, and displacement. Communities are still living in dire conditions even after the divide of the country in 2011. Both Sudan and South Sudan are still receiving humanitarian aid due to continued conflict, insecurity, vulnerability and displacement. Nonetheless, the situation in the two countries does not seem to be improving, even though South Sudan has become an independent country after decades of fighting for independence. Conversely, the humanitarian situation in some parts of Sudan has noticeably deteriorated in the past year, particularly in Darfur and in the transition zone on the border with South Sudan. Furthermore, during the writing of this thesis, fighting has erupted in the South Sudanese capital Juba between two ethnic groups within the government, spreading to most of the country and causing yet another humanitarian emergency (Reliefweb, 3 Feb 2014).

While both humanitarian actors and scholars have been trying for years to figure out how to improve humanitarian response, the international community has continued to repeat the same mistakes over and over again. Some mistakes can have dire consequences for affected populations. The former Sudan is a prime example of the ineffectiveness of humanitarian aid. While humanitarian aid itself has not caused any of the complex emergencies in the former Sudan, it has repeatedly failed to intervene effectively and fulfil the primary objectives of humanitarian aid: to save lives, alleviate suffering and maintain human dignity of populations affected by conflict or a natural disaster. OLS was one of the first multilateral humanitarian operations after the end of the Cold War; and one of the lengthiest ones. It was launched in 1989 as a response to a widespread famine which affected millions of people in southern Sudan and resulted in 250,000 deaths. The famine was caused by a combination of factors, such as the on-going civil war between government forces and their opposition - the Sudan People's Liberation Army (SPLA, also sometimes called Sudan People's Liberation Movement, SPLM), and several years of successive drought. While there were some success stories on the micro level, overall, the operation was highly criticized and rated as ineffective. In fact, a second famine developed in 1998 while OLS was still on-going, and it resulted in 
another 100,000 casualties (Bauman and Deng, 2009, p. 3). I provide more detailed analysis of the ineffectiveness of humanitarian aid provided during OLS in chapter three. Another humanitarian and political failure of Sudan has been the genocide in Darfur, a region in the western part of Sudan, which started when OLS was coming to an end. The crisis, which developed between 2003 and 2005 (and is still on-going), was caused by ethnic violence between the Arab and the African populations in Darfur. However, one of the worst humanitarian catastrophes in the modern history could have been prevented (or at least diminished) by a more adequate and timely international response. The international community repeated many of the same mistakes of OLS, despite having more experience in responding to complex emergencies in both Sudan and in other parts of the world. These circumstances in Darfur resulted in 400,000 casualties, extensive human rights abuses, and widespread displacement.

Since the end of OLS in 2004, the humanitarian system has undergone a transformation. The UN implemented a set of Humanitarian Reforms in 2005 in order to improve the effectiveness of their response. Recently, the international community, particularly OCHA, recognised that in order to improve effectiveness, it is not only necessary to improve standards for providing humanitarian aid, but also to systematically evaluate humanitarian action and learn from previous mistakes. Nonetheless, humanitarian actors today are challenged with some of the same issues in the former Sudan as they were during OLS and during the Darfur crisis. Therefore, addressing the failures of the past is important for the understanding of the current situation and, perhaps, identifying the issues early on could help to prevent repetition of the same mistakes in the future. Humanitarian effectiveness is a new concept, proposed in 2013 at a series of meetings organized by OCHA, leading up to the 2016 World Humanitarian Summit (WHS). Even though humanitarian effectiveness has yet to be clearly defined, participating actors have identified and proposed 'Elements of [Humanitarian] Effectiveness', the core issues that need to be addressed, namely: performance, accountability, coordination, contextualization, principles and standards, relevance, participation, capacity, resilience and preparedness, innovation, and access.

This thesis will use these OCHA Elements of Effectiveness as a framework in order to critically analyse humanitarian effectiveness in the former Sudan, specifically in southern Sudan during OLS (1989-2004) and during the most critical years of the Darfur crisis (20032005). Although OLS and the Darfur crisis were separate emergencies, and the Darfur region in the West of Sudan was not part of OLS mandate, both emergencies involved the same 
actors, the GoS and the SPLA. Furthermore, the Darfur crisis developed when OLS was coming to an end and the North-South peace talks were underway. The international community hesitated to intervene in Darfur for over a year as it did not want to compromise the peace process between the North and the South of Sudan. The international community again failed to respond effectively, and this delay contributed to a humanitarian catastrophe.

This thesis is based on data obtained from evaluations of humanitarian action conducted during OLS and in Darfur by several humanitarian agencies themselves, as well as through reflections on humanitarian responses in academic literature. Due to the time constraints of the project, I have based the thesis on secondary analysis. This meta-analysis has, however, enabled me to identify not only the shortcomings of OLS and Darfur in terms of humanitarian effectiveness, but also the lack of learning curve between the two operations, and the importance of evaluation in for improving humanitarian effectiveness. OLS, which was the first multilateral humanitarian operation after the end of the Cold War and which is perceived as one of the biggest failures in humanitarian aid history, will be used as a starting point. Consequently, I will use the case of Darfur in order to answer the following research questions: How has humanitarian effectiveness evolved in the former Sudan since the launch of OLS? Have lessons been learned from the failures of OLS?

The thesis is divided into three parts. In order to understand the shortcomings of the international responses to the crises in the former Sudan, it is important to explain global developments in the humanitarian sector after the end of the Cold War and the response of the humanitarian community on the policy level. Therefore, in the next chapter I will explain how humanitarian aid has evolved after the end of the Cold War in regard to complex emergencies, and why the international community has felt the need for evaluating and improving humanitarian effectiveness. Consequently, in the third and the fourth chapters I will critically analyse humanitarian effectiveness in the former Sudan, during OLS and in Darfur, respectively, in order to demonstrate how ineffective humanitarian aid has been and how little had changed in the international response, despite the fact that the former Sudan has been one of the largest recipients of humanitarian aid since the end of the Cold War.

I will argue that humanitarian aid has generally been seen as a failure since the end of the Cold War, and that evaluating humanitarian effectiveness is necessary for the improvement of humanitarian aid. However, complex emergencies are inherently political and require addressing their underlying socio-economic causes. Therefore, humanitarian aid cannot be 
solely blamed for the overall failures of international interventions, as it only exists alongside of crises and it is limited to saving lives, alleviating suffering of affected populations, and maintaining their human dignity. International actors mostly failed to address political problems of crises in the aftermath of the Cold War and humanitarian aid was used as the only response. Nonetheless, within the limitations of humanitarian aid, there were still many factors that contributed to ineffectiveness of humanitarian operations, particularly in the first years after the end of the Cold War.

As mentioned above, OLS was the first multilateral humanitarian operation after the end of the Cold War, and humanitarian effectiveness was really poor during OLS. However, when the crisis in Darfur broke out, the international community had more than ten years of experience in responding to complex emergencies. Yet, it again failed to respond effectively and repeated many of the mistakes of OLS. Major weaknesses of both operations were, apart from lacking political response, also problems associated with accessibility and lacking coordination and cooperation between humanitarian agencies. On the other hand, some improvements were made in Darfur compared to OLS, such as there were no more claims of humanitarian aid influencing conflict. The shortcomings of both operations will be demonstrated through individual OCHA Elements of Effectiveness. While in the third chapter I will analyse humanitarian effectiveness during OLS, the fourth chapter will evaluate humanitarian effectiveness during the Darfur crisis and compare it to OLS.

Although some improvements have been finally made in terms of humanitarian effectiveness in the past decade (thus after OLS and the peak years of the Darfur crisis), such as through the 2005 Humanitarian Reforms (particularly the cluster approach) and currently the process of developing humanitarian effectiveness standards is underway, there are still major problems in the humanitarian sector, such as insufficient funding mechanisms and inability of the UN to resolve prolonged crises on a political level. Furthermore, humanitarian aid is still characterised by a lack of data. Therefore, I assert that it is important to develop better standards for humanitarian response based on reflections on past operations. OCHA-proposed Elements of Effectiveness give the impression of a useful starting point for developing such standards. Unified standards for monitoring and evaluation of humanitarian operations on an on-going basis will enable the international community to learn from past mistakes and to effectively fulfil the primary objectives of humanitarian aid. 


\section{New Humanitarianism and Humanitarian Effectiveness}

In order to analyse humanitarian effectiveness in southern Sudan and Darfur, it is important to outline developments in the global humanitarian realm and the international policy response to these developments after the end of the Cold War until today. Also, in summarizing these developments and the policy level of the global response, this chapter will lay a theoretical foundation for the analytical chapters on OLS and Darfur.

The end of the Cold War caused a major shift in the world order which was also followed by a significant change in the realm of humanitarian aid. Joanna Macrae calls this changing arena of humanitarian aid after the end of the Cold War 'new humanitarianism' (Macrae, 2002, p. 5). This expansion of the humanitarian sector, caused by the growing numbers of people in need (due to greater incidence of natural and man-made disasters in the last few decades) and by opening of international borders, has also led to increased funding requirements for humanitarian operations. While during the Cold War humanitarian aid constituted only a small part of international aid, today official humanitarian aid (official bilateral emergency and disaster relief reported by the Development Assistance Committee of the Organisation for Economic Cooperation and Development (OECD/DAC)) accounts for approximately ten per cent of overall international assistance. For some donors it is, however, much higher. For instance, the ratio of humanitarian assistance in overall foreign aid is close to 20 per cent in some donor countries, such as the United States, Sweden, and Norway. Total humanitarian aid (which also includes aid raised and provided by NGOs), nonetheless, accounts for approximately 14 per cent of international aid; and the need for more relief keeps growing in the developing world (Riddell, 2007, p. 445).

Furthermore, as humanitarian actors are no longer restricted by the notion of absolute sovereignty, it has become possible for them to access the most vulnerable populations in the midst of conflicts. While during the Cold War only a few agencies, such as the Red Cross, were able to access affected populations (mostly only on the periphery of conflicts, or in neighbouring countries), after the end of the Cold War the numbers of actors involved have multiplied. Today, there are four main types of actors involved in humanitarian responses. Apart from the traditional Red Cross, there are multilateral actors (such as various UN and European Union (EU) agencies), official donors (governments, businesses and individual donors), and non-governmental organisations (NGOs) (Riddell, 2007, p. 311). The importance of NGOs has risen quite dramatically in the new humanitarian system. In 
contemporary crises, even official assistance is often channelled through NGOs in the form of subcontracting from multilateral agencies, such as the UN and the EU. For instance, the UN provides funding and NGOs implement humanitarian aid programmes (Riddell, 2007, p. 317). 'New humanitarians' had however little or no previous experience of working in the midst of conflicts when the Cold War ended. Therefore, their work in the aftermath of the Cold War was largely ad hoc and subsequently, their actions were often criticised for negative effects on conflict in the 1990s, and later for overall ineffectiveness of their work.

Humanitarian aid is intended as a short-term solution to help vulnerable populations affected by a crisis. However, due to the nature of contemporary crises in some parts of the world, and particularly in some parts of Africa, there are people, who have depended on humanitarian aid for many years, even decades. Humanitarian effectiveness has been called into question by the aid community as well as by academics since the 1990s. It was increasingly criticised particularly during interventions in Bosnia, Somalia, and Rwanda (IFRC, 2003, p. 135). In this regard, negative effects of aid in regard to conflicts and protracted crises have been questioned, as well as lack of accountability and coordination, and other factors. The need for improvement of humanitarian response was particularly evident after the genocide in Rwanda in 1994 (Buchanan-Smith, 2003, p. vi) where the international community failed to intervene effectively in the initial stages of the crisis, as well as some humanitarian agencies later contributed to exacerbating the conflict by aiding militant refugees in camps in neighbouring Zaire.

Nonetheless, soon after the end of the Cold War, the international community recognised the need to reform the humanitarian system due to the opening of international borders and subsequent broadening of the humanitarian arena as a result of better accessibility of populations affected by complex emergencies, and also due to the multitude of new actors, such as NGOs. In December 1991, the UN General Assembly introduced its Guiding Principles for humanitarian emergency assistance in the form of resolution 46/182. The resolution stresses the importance of humanitarian assistance for civilian populations affected by complex emergencies, the importance of coordination, cooperation and leadership, respect for humanitarian principles, disaster prevention and preparedness, respect for international and national laws, support for the transition to recovery and long term development, and the central role of the UN in terms of leadership and coordination (UN GA, A/RES/46/182, 1991). 
Humanitarian principles, mentioned above, have been the traditional guidelines for humanitarian actors since their introduction by the Red Cross in 1965. While the Red Cross adheres to seven humanitarian principles, UN resolution 46/182 only emphasizes the importance of the first three, namely: humanity, impartiality, and neutrality. The principle of humanity (also called the humanitarian imperative) stresses the right of every human being to receive humanitarian aid in cases of human suffering. The principle of impartiality means that humanitarian aid is provided on the basis of need with no discrimination to nationality, race, religion, class, or political views. The principle of neutrality states that humanitarian actors should remain neutral and not favour any one side of a conflict (Red Cross Fundamental Principles website, OCHA Humanitarian Principles website). Later (in 2004), the UN also acknowledged the importance of the fourth humanitarian principle - the principle of independence (UN GA Resolution 58/114). Specifically, aid should be provided independently, free from political, economic, military, or other objectives (Red Cross Fundamental Principles website, OCHA Humanitarian Principles website). Compliance with humanitarian principles is still today seen as fundamental for effective humanitarian coordination and for the establishment and maintenance of access to affected populations by the UN and other agencies (OCHA, Humanitarian Principles, 2010).

The need for greater accountability of humanitarian actors and for the improvement of their performance has led to the development of the Code of Conduct for the International Red Cross and Red Crescent Movement and NGOs in Disaster Relief and to the establishment of different initiatives, aimed at preventing negative effects of humanitarian action and at improving humanitarian work, such as the Humanitarian Accountability Partnership (HAP), Do No Harm, and The Sphere Project. Particularly the 'Sphere Standards', are widely accepted by the humanitarian community. The Sphere Project, a humanitarian policy initiative, was launched in the second half of the 1990s by a group of humanitarian agencies, including the Red Cross. It is aimed at improving quality and accountability of humanitarian assistance provided in both natural disasters and complex emergencies. The 'Sphere Standards' (Humanitarian Charter and Minimum Standards in Disaster Response), published in 2000, are based on the combination of humanitarian principles, human rights (ICRC Code of Conduct and international human rights law), and the international refugee law. Sphere promotes the right for every person affected by a complex emergency or a natural disaster to receive assistance in times of emergency, particularly in order to fulfil people's basic needs, such as water, sanitation, food and nutrition, shelter, and health services. It also promotes 
long-term food and livelihood security (Sphere, 2000, p. 5). However, adherence to the Sphere Standards is voluntary and there are no repercussions for humanitarian actors who do not comply with them. Furthermore, efforts for greater inter-agency learning exchange have resulted in the creation of networks, such as Active Learning Network for Accountability and Performance in Humanitarian Action (ALNAP) (IFRC, 2003, p. 135).

In 2005, the UN recognised the need for a more adequate response to humanitarian crises, as the resolution 46/182 proved insufficient, and introduced the Humanitarian Reforms process. It was aimed at improving "the effectiveness of humanitarian response through greater predictability, accountability, responsibility and partnership" (IASC website). As one of the major issues in international response has been insufficient funding, the reforms involved the creation of the Central Emergency Response Fund (CERF) in 2006 which serves as a reserve pool of funding for humanitarian emergencies. CERF is annually replenished through donations from governments, private sponsors, and foundations, and its primary responsibility is to enable a timely and reliable response to natural and man-made disasters (CERF website). Humanitarian reforms also included the introduction of the cluster approach which targets the need for better coordination and cooperation between different humanitarian actors. It is based on sectorial division of labour between different agencies under the leadership of the OCHA Emergency Relief Coordinator (IASC website).

There is, however, still a lack of agreement on how to achieve humanitarian objectives in practice and how to assess the effectiveness of their implementation. Various actors of the humanitarian realm have differing opinions on how to achieve better humanitarian effectiveness, ranging from achievements of aid (how funds had been spent), to how many people have been helped, as well as based on effects on conflict, protection of civilians, and advocacy. There are also different views on the convergence of humanitarian aid with political processes and military involvement (Riddell, 2007, p. 313). Until now, there have not been many attempts to define humanitarian effectiveness or suggestions on how to measure it. Although there is a lot of academic literature on aid effectiveness, it mostly concerns development aid. The provision of humanitarian and development aid is often interconnected, particularly in underdeveloped countries with fragile environments, but the objectives and evaluation criteria for development and humanitarian aid are quite different. A consensus for defining humanitarian effectiveness has not been reached so far. 
The humanitarian community has recognised the need for evaluation of humanitarian operations in order to learn from past mistakes and improve humanitarian effectiveness of future operations. While the work of aid agencies has been criticised for numerous reasons (as mentioned above), there has generally been a lack of data on overall humanitarian responses which contributed to difficulties with assessing humanitarian effectiveness objectively. Furthermore, it is essential to find a link between the aid provided and the outcomes achieved. On the other hand, humanitarian actors have also acknowledged the difficulties of measuring the effectiveness of humanitarian operations. Some evaluations have been provided by different agencies over the years, but their quality, scope and focus vary, as do the evaluation criteria used in individual reports. Riddell suggests that one has to adopt a holistic approach when assessing a disaster or emergency and evaluate the effectiveness of aid provided by all actors involved, combined, and review the overall impact, not only particular outcomes by individual agencies (Riddell, 2007, p. 325). Similarly, Hofmann stresses the importance of system-wide evaluations. One needs to consider collective outcomes, as well as the broader political dimensions of the environment humanitarian aid operates in. Also, process and operational effectiveness need to be considered as some evaluations are too narrow and only results-driven. One has to evaluate both processes and impact. Therefore, an assessment of the situation should be conducted before the launch of a humanitarian operation, then agencies should carry out an on-going analysis throughout each operation, and finally, an analysis of the impact of an operation should be completed with regard to the impact of each intervention (Hofmann, 2004, p. 1-2).

The only systematic framework for evaluating humanitarian effectiveness in complex emergencies, so far, has been the collaborative work of the United Kingdom-based Overseas Development Institute (ODI) and the OECD/DAC, Guidance for Evaluating Humanitarian Assistance in Complex Emergencies, published in 1999. The OECD/DAC guide recommends that humanitarian aid provided in complex emergencies should be evaluated on the basis of efficiency, effectiveness, impact, sustainability, and relevance (OECD, 1999, p. 22). Effectiveness is defined by the OECD as "the extent to which the activity's stated objectives have been met" (OECD website). The publication suggests that evaluating humanitarian effectiveness requires the evaluator to consider the initial causes of complex emergencies, namely political instability and armed conflict (OECD, 1999, p. 5-6). It also recommends that evaluators assess the 'humanitarian space' (determined by the accessibility of affected populations, the level of human rights abuses and the measures taken to provide protection to 
affected populations, as well as the accountability of aid agencies) in which aid agencies operate (OECD, 1999, p. 15-17). Furthermore, the paper suggests evaluating the effects of aid on war (the extent of aid on the war economy through diversion or taxation of aid), as well as considering displacement of populations, both refugees and IDPs. Finally, the report recommends evaluating the distribution of aid (OECD, 1999, p. 22).

The OECD/DAC also recommends that, in order to improve humanitarian effectiveness, it is essential to select criteria for evaluation of humanitarian operations. However, humanitarian aid monitoring and evaluations have been less systematic than evaluations of development aid effectiveness (OECD/DAC, 1999, p. 2). This might also be due to the fact that humanitarian aid is more complicated to evaluate than development aid. The main objective of development aid is economic growth and the alleviation of poverty, and the principles for improving aid effectiveness are ownership, alignment, harmonisation, managing for results, and mutual accountability, as stated in the Paris Declaration (OECD, 2005). However, the main objectives of humanitarian aid are to "save lives, alleviate suffering and maintain human dignity during and in the aftermath of natural and man-made crises", as stated in resolution 46/182, and it can only be estimated how many lives have been saved or how many deaths have been prevented through the provision of humanitarian aid (Riddell, 2007, p. 311).

The international community did not recognise the importance of a unified approach for evaluating humanitarian effectiveness, until recently. Even though, the OECD/DAC guide has not been used systematically and it is today perceived by OCHA as inadequate for evaluating humanitarian effectiveness, it undoubtedly represents the first step towards improving it. The OECD/DAC criteria have been used as guiding principles for evaluation by some agencies in the past. However, today they are perceived as being an insufficient, developmentally-oriented framework which is focused on outcomes and not processes, and which is missing key elements for evaluating humanitarian effectiveness, such as preparedness, sustainability, accountability, transparency, and an orientation to the needs of affected people. Therefore, the framework is not suitable for evaluating humanitarian effectiveness (OCHA, March 2013, p. 2, 4). Also, provision of humanitarian aid is traditionally based on humanitarian principles, particularly on the core principles of humanity, impartiality, neutrality, and independence, which the OECD/DAC guide does not take into account. It would seem logical to base humanitarian effectiveness evaluations on humanitarian principles in terms of numbers of saved lives and the fulfilment of basic human 
needs. However, Riddell argues that this view would be too simplistic, as the consequences of humanitarian action are not as clear and are more complex than it might seem at first (Riddell, p. 312).

As of late, there has finally been a lot of debate on humanitarian effectiveness in the aid community, after the UN Secretary-General published the 'Five-Year Action Agenda' in 2012. It calls for a more global, accountable and robust humanitarian system. To achieve this, the Secretary-General expressed the need for promoting the agenda for humanitarian effectiveness (UN, 2012, p. 7). Valerie Amos, UN OCHA Under-Secretary General and Emergency Relief Coordinator has recently addressed humanitarian effectiveness as "one of the most important challenges for the humanitarian sector" (DARA HardTalk, 15 October 2013), as the humanitarian community is lacking a common set of performance standards. It has not yet been established what humanitarian effectiveness actually means, how to define it, or how to measure it. It has been agreed at the OCHA Consultative Workshop on Humanitarian Effectiveness in March 2013 that more research has to be done, and humanitarian effectiveness has been set as the one of the main agendas for debate at the first ever WHS which will be held in Istanbul, Turkey in 2016. The goal of the WHS will be to strengthen humanitarian aid and promote a "global agenda on humanitarian aid transparency and effectiveness", according to the UN Secretary-General's Five Year Action Agenda. It is also hoped to agree on a unified definition, approach, and evaluation criteria for humanitarian effectiveness (OCHA, 21 March 2013, p. 1).

The term 'humanitarian effectiveness' was preferred by participating actors of the May 2013 workshop to 'humanitarian aid effectiveness' in order to avoid confusion with 'aid effectiveness' which is concerned with development aid (OCHA, May 2013, p. 6). Participating actors agreed that the humanitarian effectiveness agenda has to be "embedded in the overall economic, political and security context" of complex emergencies (OCHA, May 2013, p. 8). They proposed a set of core issues which need to be addressed. These 'Elements of Effectiveness' are performance, accountability, coordination, contextualization, principles and standards, relevance, participation, capacity, resilience and preparedness, innovation, and access (more detail provided in 'Annex 1 - Elements of Effectiveness', OCHA, 2013).

In order to develop a unified approach and improve evaluations of humanitarian effectiveness, recent debates have also suggested combining qualitative and quantitative methods, if possible (OCHA, March 2013, p. 4). Nevertheless, humanitarian effectiveness is 
often hard to assess in quantitative terms as data provided by agencies are often inaccurate and sketchy (Riddell, 2007, p. 312). There have been systemic problems with data collection and analysis, as the humanitarian sector is multi-dimensional and decentralised and different actors have been using varied approaches (OCHA, March 2013, p. 2). Therefore, it is necessary to develop a unified approach for evaluating humanitarian effectiveness, also because evaluations provided by individual agencies are quite often one sided and can be misleading. The number of evaluations has grown but their quality varies. They are often designed to please their donors and therefore promote partial successes, but it is hard to say if individual agencies or their projects have contributed to the overall effectiveness. In the past, projects of individual NGOs have often overlapped and agencies lacked a coordinated systematic approach which has sometimes led to agencies concentrating in easily accessible and relatively safe areas, while the most vulnerable people were often neglected and left unattended. So, while agencies were reporting successes in terms of numbers of lives they had saved, many other people had meanwhile continued to suffer and die (Riddell, 2007, p. $312)$.

In regard to humanitarian effectiveness in complex emergencies, it is also important to address the relationship between humanitarian actors and other actors in the field. As the world has been changing, the lines between humanitarian actors and other intervening agents involved have been blurring, as well. Humanitarian agencies working in insecure environments of complex emergencies often cooperate with peacekeeping forces in order to protect civilians. Duffield and others perceive securitization of aid, the convergence of aid and security, as means for promotion of human rights and protection of vulnerable populations and a potential for decreasing of conflicts in unstable and insecure environments (Duffield, 2001, p. 310). Conversely, humanitarian operations have also sometimes served for the achievement of political interests of actors involved. Western governments, particularly the United States, have used the pretext of humanitarianism for the pursuit of their political and military objectives (Macrae, 2002, p. 16). While humanitarian minimalists believe that humanitarian aid should strictly comply with humanitarian principles and maintain its neutrality, humanitarian maximalists promote the use of aid for building peace. They argue that humanitarian aid provided in complex emergencies is never provided in a vacuum and therefore it cannot be neutral. The prevalent view today is that humanitarian aid has to address underlying and immediate causes of crises it operates in, in order to be effective (Riddell, 2007, p. 326). Nonetheless, OLS failed to address the underlying causes of the 
South Sudan crisis, and it failed to effectively fulfil the objectives of humanitarian aid (which will be demonstrated in the next chapter).

Overall, the developments in the international realm since the end of the Cold War led to major changes in the response of humanitarian actors to complex emergencies. However, despite these changes and developments of different policies, norms and standards in the humanitarian realm, 25 years after the end of the Cold War, humanitarian aid is still not effective. This thesis stresses the importance of monitoring and evaluating humanitarian operations as an on-going learning process for improvement of humanitarian response. It also supports the development of a better set of norms/standards/policies for multilateral responses to complex emergencies, such as South Sudan and Darfur. There is only so much humanitarian aid can do, it cannot resolve conflicts or prevent natural disasters, but in providing aid in an accountable and coordinated manner, with adherence to humanitarian principles, humanitarian aid can do what it is designed to do, save lives, alleviate suffering and maintain human dignity for populations affected by complex emergencies. The next two chapters will demonstrate failures of humanitarian actors in responding to complex emergencies in southern Sudan and Darfur. It the case of OLS, the failures can be blamed on the inexperience of humanitarian actors, but in the case of Darfur, many of the failures could have been prevented if only the international community had reflected on their mistakes from OLS. Therefore, it is important to analyse humanitarian effectiveness of past complex emergencies and learn from them in order to improve humanitarian effectiveness in the former Sudan and in other fragile environments today. 


\section{Humanitarian Effectiveness during Operation Lifeline Sudan}

This chapter will analyse humanitarian effectiveness during OLS. Operation Lifeline Sudan was launched in response to famine which developed in parts of southern Sudan in the second half of the 1980s as a result of civil war between the government and its opposition forces in the former Sudan. The operation has been extensively criticised both while it was still unfolding and after it ended. While some, such as Autesserre, perceive OLS as one of the greatest failures in humanitarian aid history, despite its scope (Autesserre In: Bauman and Deng, 2009, p. 3), Duffield suggests that OLS was partially successful. There is an undeniable contribution of saving lives, as without international relief many more people would have died as a consequence of conflict and famine. On the other hand, a lot more lives could have been saved if the UN would have responded in a more adequate and effective manner, particularly in terms of food security. Even though food aid delivery is of primary importance in complex emergencies, other aspects, such as logistical support, water, and sanitation were largely neglected during OLS (Duffield, 2000, p. 172-173). As mentioned below, humanitarian aid deliveries were problematic not only due to restrictions imposed by the Government of Sudan (GoS) in southern Sudan throughout most of OLS, but also due to inexperience and mistakes of aid agencies. Anderson believes that the fact that there were some success stories on the micro-level does not compensate for the overall failures of OLS. She emphasizes the importance of the macro-level for the evaluation of humanitarian aid as humanitarian assistance can have negative effects on conflict, as well as an inappropriate or missing multilateral response can have dire consequences for the affected population (Anderson cited In: Bauman and Deng, 2009, p. 3).

In order to analyse if humanitarian effectiveness in the former Sudan has improved since the end of OLS in 2004 and if the international community has learned from its previous mistakes, this chapter will identify factors that led to the failures of the operation using the OCHA Elements of Effectiveness framework outlined in the previous chapter. Namely, this chapter will analyse performance, accountability, coordination, contextualization, principles and standards, relevance, participation, capacity, resilience and preparedness, innovation, and access during OLS. In this chapter, I argue that overall humanitarian effectiveness during OLS was extremely poor, particularly due to inexperience of humanitarian actors in responding to complex emergencies after the end of the Cold War. The main shortcoming of the operation was the failure to address the political aspect of the crisis as the international 
community believed that humanitarian aid could resolve the crisis. Furthermore, OLS experienced major problems with accessibility. Problematic was late timing of the operation and insufficiency of the response, as well as humanitarian agencies did not work in an accountable and coordinated manner. I will provide further detail on these shortcomings after outlining the overall context before and during OLS.

\subsection{OLS Context}

OLS was established in 1989 during a time of major historical challenges as the Cold War was coming to an end. The former Sudan has a long history of humanitarian aid which had already started before the launch of OLS. However, until 1989, aid to Sudan was limited due to respecting absolute sovereignty by governments and the international community. This meant that aid was provided only to war affected populations outside of war zones with the consent of the GoS, particularly by the Red Cross. This started to slowly change during the second half of the 1980s and the Red Cross was able to access vulnerable populations in the GoS-controlled areas in the North and some parts of the South. However, areas in the South held by the opposition movement, the SPLA, stayed largely unattended by humanitarian relief due to GoS control. As a result, a famine developed in the province of Bahr El-Ghazal and was spreading to other SPLA-held provinces in the South as well. This happened due to a combination of factors, such as continuation of a long-lasting civil war between the North and the South, several years of drought, as well as the GoS deliberately denying food to people in southern Sudan as a strategy of war.

The conflict between the North and the South of Sudan is a complex issue stemming from dissimilarities between the two parts of the country, ranging from political, to ethnic, cultural, and religious differences. While Northerners are prevalently Arabs adhering to Islam, the South is inhabited mainly by black Africans who are either Christian or follow animist traditions and practice pastoralism (Macrae et al, 1997, p. 224). While the North of the country is poor in terms of natural resources and the land is not very fertile, South Sudan has an abundance of natural resources (such as water, timber and oil), and the land is quite fertile, as well. Therefore, the quantity and quality of natural resources had been another incentive fuelling the conflict, as the GoS did not want to lose naturally rich areas in the South for economic reasons and was denying SPLA's calls for independence (Duffield, 2000, p. 168). 


\subsection{Performance}

The criterion of performance is not easy to assess in this chapter as humanitarian actors working within the OLS framework had no previous experience working directly in the midst of conflict and no precedent to follow. Humanitarian work during OLS was mostly executed on an ad hoc basis. OLS was the first UN humanitarian operation to directly challenge the absolute sovereignty principle, as the UN and NGOs were directly involved in cross-border aid delivery. Never before were multilateral organisations able to provide aid in the midst of an internal conflict. With the ending of the Cold War, the international situation was easing from the mid-1980s onwards, and some independent, previously only developmentally oriented NGOs expanded their involvement in cross-border relief work in Africa already prior the beginning of OLS (Duffield, 1994, p. 7). After the end of the Cold War, the numbers of NGOs grew significantly. Some of them worked independently, such as Médecins Sans Frontières (MSF), while others were working through subcontracting from the UN. However, as they had little or no previous experience working in the field, it led to a range of mistakes. Also, as mentioned above, the establishment of a relationship with a non-state actor, such as the SPLA was another unprecedented experience for OLS, as this relationship gave the SPLA recognition and legitimacy by the international community (Bradbury et al, 2000, p. 27). This relationship can be seen as another sign of the changing international realm after the end of the Cold War. The development of this relationship was also the first step towards South Sudan's independence, together with the 'Agreement on Ground Rules', signed in 1995 between the SPLM and OLS. The bilateral agreement was to strengthen and support the OLS mandate and its support for humanitarian principles (Bradbury et al, 2000, p. 30), as well as for the Geneva Convention and Protocols in the southern sector. It also enabled better access to SPLA-controlled areas (Barltrop, 2011, p. 79).

\subsection{Accountability}

Accountability did not seem to concern the international community much in the first years of OLS. However, it is not easy to analyse for the overall lack of data. It wasn't until the late 1990s when critics such as Terry and Anderson started to point out negative effects of aid on conflict and called for better accountability of aid agencies and individual aid workers. As mentioned in the previous chapter, Anderson's 'Do No Harm' approach has been one of many attempts on how to improve certain aspects of humanitarian effectiveness. She calls for 
better accountability of aid workers and suggests how to practically minimise negative effects of aid by learning from previous mistakes, such as diversion of relief goods, lack of local ownership, or uneven distribution (Anderson, 1999, p. 38-46). Particularly diversion and manipulation of aid was a major issue during OLS. Sometimes this happened voluntarily through SPLA family members, but mostly aid was diverted by force (Duffield, 2000, p. 185). Both GoS armed forces and the SPLA looted OLS and UN relief storage centres, convoys or villages that had just received aid, as well as relief was being 'taxed' from recipients by warring factions. The capacity for diversion was increased by negotiated access and aid being distributed to civilians through locally controlled aid organisations, such as the Sudan Relief and Rehabilitation Commission (SRRA) which worked closely with local military forces (Barltrop, 2011, p. 82-83). Even though the diversion was neither systematic, nor constant, it still accounted for 30 to 40 per cent of total aid delivered (Barltrop, 2011, p. $84)$.

Furthermore, through the lack of protection and extensive diversion of relief, aid became an economic resource and a part of the war economy (Shearer, 2000, p. 190). Terry believes that when aid becomes a resource in a conflict environment, the continuation of war is more desirable than peace itself, particularly for some powerful individuals (Terry, 2002, p. 2). Contradictorily, Shearer contends that even though some individuals might have profited from the war in Sudan, this had only a minor impact on the overall development of the conflict (Shearer, 2000, p. 194-195). Although aid had become a resource due to the lack of other resources (Duffield, 2000, p. 191), it did not have an effect on the continuation of the conflict for three reasons. First, the crisis was sustained for several decades already before the beginning of OLS with no help from the outside; second, the amounts of aid provided to Sudan during OLS were not even meeting the basic needs of the struggling population; and finally, the SPLA was also present in areas that had not been receiving aid from OLS (Duffield, 2000, p. 177; Shearer, 2000, p. 196). Nonetheless, Duffield agrees with Anderson that aid agencies and individual workers should be responsible and accountable for their actions and they should be aware of potential negative effects of their actions and try to prevent them. He also expresses the need for systematic monitoring and evaluation of aid operations. However, OLS mostly lacked data and transparency (Duffield, 2000, p. 196). Similarly, Marriage suggests that aid agencies often hide behind humanitarian principles when it comes to accountability for their actions, but she believes that they do not always follow them (see below in section 3.6.) (Marriage, 2006, p. 3). Furthermore, Rhodes suggests 
that agencies do not acknowledge the needs of aid recipients and are only accountable to their donors (Rhodes, 2002, p. 12).

Nonetheless, Shearer believes that the influence of aid on conflict gets exaggerated by both academics (such as Anderson) and aid agencies themselves. Aid agencies tend to overestimate their influence in order to promote their objectives, fulfil donor agendas, or to promote their public image. According to Shearer, this overestimated portrayal of humanitarian aid suggests that aid could be a solution for a complex emergency (Shearer, 2000, p. 196-199); but Sudan is the ultimate example contradicting this belief. Humanitarian aid cannot be the only solution for a complex emergency, as it is only able to address the symptoms of an emergency and it does not tackle the underlying socioeconomic causes of conflicts (Shearer, 2000, p. 196-199). Still, humanitarian aid has quite often been the only international response to complex emergencies, and Sudan was one of them. Humanitarian aid should not try to resolve a conflict and only adhere to its primary objectives of saving lives and alleviating suffering of a civilian population affected by conflict. Otherwise, according to Shearer, it can have dire consequences for the affected population and also for further development of a country (Shearer, 2000, p. 200). Sudan desperately needed a political solution and it was not until 2001 when the international community recognised this and started looking for a peace resolution. Using humanitarian aid as the only solution to political crises (or the failure of finding an effective political solution) is a recurring pattern in the former Sudan. It contributes to lowering humanitarian effectiveness. It will particularly become clear in the following chapter, as in Darfur the failure of the international community to intervene contributed to the overall extent of the tragedy.

\subsection{Contextualization}

Contextualization is concerned with the approach used by the international community, in other words, whether it was appropriate in the given context (OCHA, 2013, p. 8). As there was no precedent to follow, the framework of OLS and other humanitarian operations in the aftermath of the Cold War was based on the natural disaster model of the Cold War era. Duffield perceives this logic as an operational failure, as this model, designed to respond to floods and droughts, pays very little attention to socioeconomic and political factors which are central to complex emergencies (Duffield, 1994, p. 3). As mentioned above, OLS was established during a time when it was believed that humanitarian aid could be a solution for 
complex emergencies. OLS failed to address the underlying factors that caused the first famine; it only addressed the consequences (high mortality statistics) where the UN should have put political pressure on the GoS who's war strategy was one of the main reasons for the development of the famine, in the first place (Keen, 1994, p. 116).

\subsection{Relevance, Resilience and Preparedness}

In the humanitarian effectiveness context, relevance is concerned with the response of the international community to a crisis, specifically, whether it was or was not timely, appropriate and adequate in the given context (OCHA, 2013, p. 8). Particularly the timing of the operation was closely related to resilience and preparedness in the case of OLS. The initial timing of the international response was quite problematic due to the development of the crisis before the official end of the Cold War. The famine in the Bahr El-Ghazal province started developing in 1986 as a result of the reasons listed previously, in addition to crumbling infrastructure in southern Sudan, and particularly due to extensive displacement. OLS was perceived by some critics as 'too little too late'. A famine was declared by the international community in 1988 and the UN initially tried to negotiate with the GoS, but their efforts were ineffective as the GoS did not want to abandon its war strategy of denying food to populations in SPLA-controlled areas. Therefore, OLS was not launched until almost a year later (Efuk, 2007, p. 50). By that time, a famine had developed on a large scale, and in the end it accounted for approximately 250,000 victims. A second famine in Bahr El-Ghazal had developed mainly as a consequence of OLS failure. Another 100,000 people died despite the size of the operation and the presence of aid agencies in the country (Rhodes, 2002, p. 2). This was largely caused by the adoption of the relief-to-development continuum in the second part of the 1990s and subsequent decrease of humanitarian aid, as well as by GoSimposed restrictions (see below).

The international community in the post-Cold War era believed that humanitarian assistance itself could help the promotion of peace in unstable parts of the world (Duffield, 1994, p. 7). However, Barltrop asserts that the OLS framework was a hindrance for conflict resolution, as it contributed to depoliticization of the crisis; negotiations between the UN and the GoS focused primarily on humanitarian action and constituted mainly of negotiating access for aid deliveries (Barltrop, 2011, p. 91). The substitution of lacking political action with aid was later criticised by many, such as Bradbury. He finds it problematic as the mandate of OLS 
was not established under Chapter VII of the UN Charter and humanitarian aid was the only international response to the conflict and extensive human rights abuses on both sides of the conflict (Bradbury et al, 2000, p. 27).

OLS was initially meant to be a short-term (six-week) operation of food aid delivery to famine-stricken areas, as the civil war was thought to have ended. However, the UN underestimated the situation. Shortly after the launch of the operation fighting in the area reescalated and OLS became more problematic (Van Voorhis, 1989, p. 35). The international community had no experience with humanitarian interventions, and 'mission creep' mandates were very common in the aftermath of the Cold War. As the operation was extending (in terms of its duration as well as its scope), its mandate was widening as well. Humanitarian aid became a tool for political manipulation by international actors as well as by the GoS. The situation would have needed separate political diplomacy, but the UN failed to recognise this and believed that a humanitarian response would be sufficient (Bradbury et al, 2000, p. 27). This notion is in disagreement with the traditional humanitarian minimalist view which is based on the respect for humanitarian principles and primary objectives of humanitarian aid. The widening of the OLS mandate and its politicised function directly challenges the principle of neutrality.

\subsection{Principles and Standards}

OLS was primarily based on traditional humanitarian principles, particularly on the four core principles, namely humanity, impartiality, neutrality, and independence. The traditional humanitarian principles were established by the International Committee of the Red Cross (ICRC) in 1965, thus still during the Cold War. As the OLS framework was also developed before the end of the Cold War, it is based on the traditional humanitarian minimalist view. Humanitarian minimalists, such as Levine or Shearer, believe that adherence to the principles is the only way how to stay true to primary objectives of humanitarian aid, namely to save lives and alleviate suffering. The mandate of the operation particularly stresses the importance of its neutrality (Bradbury et al, 2000, p. 30). Levine perceived the maintaining of neutrality and impartiality as extremely important in southern Sudan, in order to keep the trust of all warring factions (Levine, 1997, p. 9). Maintaining neutrality allows humanitarian agencies to access people in need when other actors cannot. Also humanitarian aid in Sudan allowed UN agencies to lead dialogue with warring factions. However, this was very 
difficult, as the GoS perceived many humanitarian agencies as biased and supporting the SPLA. Very important was also the humanitarian imperative based on the principle of humanity, namely the right of all civilians in an armed conflict to receive aid. At the same time, this principle was often compromised during OLS due to the GoS' sanctions (see chapter 3.9. on 'Access'). Most humanitarian agencies, including the UN, EU and major NGOs still use humanitarian principles as the core guiding principles of their work today. However, due to the changed humanitarian environment, it is no longer enough to only follow the humanitarian principles in order to provide humanitarian aid effectively.

The international community started questioning the effectiveness of humanitarian aid in regard to humanitarian principles during OLS. Many academics, such as Keen, Duffield, Anderson, and Terry started criticising humanitarian work in the 1990s, claiming that the humanitarian realm had changed and it was no longer only the Red Cross providing aid, and one could not blindly follow the traditional principles and had to be responsible for his actions; that these principles are no longer sufficient in the complex environments and multitude of actors in contemporary crises (Terry, 2002, p. 18). One cannot be neutral, as aid is not being provided in a vacuum but in a political environment. Therefore, the provision of aid is always political. Aid becomes an integral part of a conflict and cannot be isolated from it. Anderson believes that there is a mutual relationship between aid and conflict, where relief provided in a complex emergency is influenced by conflict, as well as aid itself can influence or even prolong a conflict (Anderson, 1999, p. 1). This view is congruent with the post-Cold War belief that humanitarian aid can resolve conflicts, and therefore, aid had been used as the only response to political crises. It was not until 2001 when the international community recognised that humanitarian relief itself would not resolve the civil war in Sudan and started supporting a political solution for the crisis (Barltrop, 2011, p. 89).

\subsection{Coordination, Capacity, and Innovation}

The whole operation was lacking adequate coordination and cooperation mechanisms and it struggled from institutional amnesia. The UN had not enough capacity for the implementation of projects, so it mostly only secured access and funds, while affiliated NGOs carried out the actual relief projects (Duffield, 1994, p. 7). Apart from UNICEF, the main UN agency responsible for the coordination of the operation and the lead agency in the southern sector, OLS consisted of the WFP, the lead agency in the northern sector, and at 
times up to almost sixty other UN agencies and local and international NGOs (Barltrop, 2011, p. 76). While some agencies cooperated with UNICEF and others worked independently, overall inter-agency communication was missing. This led to surplus food aid in some areas while other areas were unaided. Most NGOs concentrated in more stable areas, while the most vulnerable areas were left unattended. This not only led to proliferation of scarce resources, but also to institutional amnesia, periodic repetition of mistakes, accented by frequent proliferation of aid workers (Rhodes, 2002, p. 11). Nonetheless, problems with coordination of the operation were further emphasized by the division of OLS in two sectors. While the southern sector had its headquarters in Nairobi (Kenya), the northern sector in the Sudanese capital Khartoum, and there was almost no communication between the two centres (Barltrop, 2011, p. 92). While the northern sector was controlled by the GoS and still respected Sudan's absolute sovereignty (a 1980s model), the southern sector, which operated in SPLA-controlled areas, developed certain autonomy from the government. Consequently, a part of Sudan's sovereignty was basically in hands of the UN. Still, as mentioned below, the operating regime was largely ad hoc due to negotiated access (Karim et al, 1996, p. 2).

Capacity building in southern Sudan was a complex issue as parts of it were severely underdeveloped already before the outbreak of the Second Sudanese Civil War in 1983. However, the conflict caused further deterioration of basic services, such as healthcare, education, or even access to clean water due to widespread displacement and disruption to infrastructure and markets. The disorder was so severe that OLS agencies were challenged every day by working in extremely dangerous conditions, with almost non-existent infrastructure. The success of OLS had been constantly challenged by operational and programmatic issues, and mistakes got periodically repeated year after year (Barltrop, 2011, p. 90). Nonetheless, capacity building was not addressed until 2001 when the international community recognised that aid will not resolve the crisis and started acting on the need for a political resolution in southern Sudan. Even though not much had changed after 2001 in terms of relief delivery within OLS, peace processes between the GoS and the SPLA started to progress outside OLS. The first step towards a peaceful resolution between the North and the South was a ceasefire in the Nuba Mountains, in the North of the country which was however outside OLS's orbit (Barltrop, 2011, p. 96). Also, the crisis in Darfur between 2003 and 2005 drew more attention to the whole of Sudan and it contributed to an overall increase in funding for both Darfur and southern Sudan, not only in terms of relief, but also recovery and development assistance (Barltrop, 2011, p. 99). 
In terms of innovation, OLS was launched by the UN in April 1989, thus before the actual end of the Cold War. While this step by the UN indicated the change in thinking about humanitarian intervention and conflict management, OLS was also different than other humanitarian interventions that followed (Rhodes, 2002, p.3). As mentioned in the previous chapter, the end of the Cold War denoted an era of 'new humanitarianism' which was characterised primarily by the changing response of the international community to intrastate conflicts and complex emergencies. While during the Cold War only the Red Cross was allowed to aid populations affected by an intrastate conflict and mainly only on the outskirts of conflicts, the end of the Cold War opened doors for other humanitarian actors and was denoted by a rapid growth of the international non-governmental sector.

As OLS was the first operation of its kind, and therefore quite innovative in regard to complex emergencies, it was also unique and different than operations that followed in terms of its framework. The mandate of the operation did not include protection of civilians, humanitarian workers, or the displaced population. The primary responsibility to protect its citizens is attributed to the government of every country. Furthermore, Sudan is a signatory of the Geneva Convention. Therefore, the GoS is to protect its citizens in times of an armed conflict. However, during OLS civilians in the South had been not only denied food and other relief supplies, they were often intentionally targeted by government forces under the pretence that they support the SPLA. Human rights of the civilian population had been repeatedly abused by the government, as well as by the rebels in the form of child soldiers, camp militarization, aid diversion, abductions, rape, and the like. Insecurity has been a massive problem in Sudan, not just for the local population but for relief workers as well, due to extensive fighting, aerial bombing and abductions (Barltrop, 2011, p 80). The international community has since learned from its past mistakes, and today protection of civilians is an integral component of every UN-mandated operation (Rhodes, 2002, p. 4).

The previous chapter stressed the importance of evaluation for the improvement of humanitarian effectiveness. However, the only systematic approach to evaluate and improve OLS was the independent OLS Review undertaken in 1995 (published by UNICEF 1996) by a team of researchers, led by Ataul Karim. The Review aimed to assess the effectiveness of meeting the needs of the war-affected civilian population in Sudan. In particular, it found problematic the division of OLS into two sectors and their different operational regimes (Karim et al, 1996, p. 2). After the Review was published in 1996, the UN attempted to improve some areas of OLS, such as accessibility, programming, distribution of relief, and 
diversion of aid, but with only little or no success due to lacking cooperation from both sides of the conflict. Most of the solutions were only temporary, as both the GoS and the SPLA kept breaking agreements and ceasefires. Furthermore, the Review failed to address OLS' lack of a political component and the scope of relief abuse by the warring parties. As Barltrop points out, the operation was lacking diplomatic political negotiations in the 1990s (Barltrop, 2011, p. 87). However, in 2001 the strategy of the UN changed quite significantly and OLS started supporting a diplomatic solution for the decades-long conflict (Barltrop, 2011, p. 89).

\subsection{Participation}

OLS was lacking ownership and leadership of the GoS. On the contrary, the GoS not only did not participate in helping its population, it was deliberately targeting the population in southern Sudan, abusing their human rights, and denying them relief provided by the international community. As the population of Sudan continued to struggle, the international community was focused solely on the provision of humanitarian aid in the first five years of OLS. However, humanitarian aid is meant to be a short-term solution to an emergency. Due to the protracted nature of the crisis, in 1994 the international community decided to adopt a strategy aimed at promoting long-term results and self-sufficiency of the local population in the South. Macrae proposed the relief-to-development strategy, adopted by OLS in the 1994, as the biggest mistake of OLS, as it derived from the 1980s natural disaster model which does not work in complex emergencies (as mentioned above) (Macrae et al, 1997, p. 225). However, Duffield is convinced that the 'continuum' thinking is a new concept stemming from the 'new aid' paradigm, as not only humanitarian aid but also development aid changed with the end of the Cold War (Duffield, 1997, p. 529). Nonetheless, Macrae also suggested that the failure of the strategy is another reason why relief by itself cannot be the solution for complex emergencies (Macrae et al, 1997, p. 225).

In the mid-1990s, it was believed that the worst emergency was over and that a longer-term approach, promoting rehabilitation, reconstruction and capacity building should be adopted (Duffield, 1997, p. 525). Another reason for changing the strategy was the false belief that the population was creating dependency on food aid provided. Duffield stresses the shortcomings of the decision to adopt the relief-to-development strategy in pointing out that relief provided was irregular, unreliable and insufficient, therefore, impossible to create a dependency on. Furthermore, the conflict was still on-going and millions of people were still in need of relief. 
With the adoption of the relief-to-development continuum, already unsatisfactory amounts of humanitarian aid further decreased (Duffield, 2000, p. 194-195). Food aid was reduced by almost 70 per cent in the second half of the 1990s (Marriage, 2006, p. 141), and humanitarian aid provided by OLS covered only approximately 20 per cent of food needs in Sudan (Rhodes, 2002, p. 9).

OLS relief-to-development strategy was supported by donor governments, the GoS and the SPLA (Efuk, 2007, p. 52), as it was believed that replacing a mostly reactive strategic framework with a more proactive one would shift the focus of OLS towards the root problems which caused the conflict (Efuk, 2007, p. 55). However, the implementation of the new strategy proved to be problematic and counterproductive, as the country was still in the midst of conflict and displaced and vulnerable people were in need of basic humanitarian aid. Efuk provides more detail on why development projects did not bring any substantial results. First, NGOs' attempts for community-based income-generating projects failed due to lack of local knowledge, lack of cooperation between agencies, the continuation of war, and also because agencies tended to set up projects in unstable areas rather than in more stable ones where they could have been more successful (Efuk, 2007, p. 61-62). Contemporary research has shown that development projects tend to be more effective in stable areas. Second, while NGOs concentrated on capacity building on the micro-level (communities, villages), the macro-level (state) had been neglected (Efuk, 2007, p. 62). Third, OLS development projects did not include local capacities on planning and implementation of projects (lack of participation). There were not suitable for the Sudanese social, economic and political context. NGO strategies lacked local knowledge and cultural sensitivity which led to mistakes, such as provision of wrong types of seeds, or neglecting local community and family structures (Efuk, 2007, p. 64-65).

Aid was distributed on the principle of targeting of the most vulnerable in each community or village. Targeting was executed through community representatives, such as chiefs or elders. Duffield finds this strategy culturally inappropriate and ineffective as supplies were distributed on the basis of kin rather than need. Furthermore, he perceives targeting insufficient in famine-affected areas where everyone was vulnerable and in need of aid (Duffield, 2000, p. 184). This strategy also created tensions between locals and NGOs. In addition, it generated tensions between aid agencies and the GoS who not only imposed further flight bans, but also some NGOs had to leave the country. These factors contributed to a worsening of the humanitarian situation in the second half of the 1990s (Efuk, 2007, p. 63- 
67). Or as Duffield puts it, the relief-to-development framework of OLS contributed to further exploitation of the southern Sudanese population. Development-boosting strategies, such as seed programmes proved counterproductive as people in some parts of southern Sudan were dying from starvation. Often they were so hungry that they ate the seeds provided instead of planting them (Duffield, 2002, p. 86). Duffield also finds problematic the timing of some projects, as seeds were often distributed after the planting season due to NGOs' lacking local knowledge (Duffield, 2000, p. 207-208). Nonetheless, even though the principle of targeting represented a form of inclusion of the local population, it failed to promote ownership of local communities and the government in the decision making process.

\subsection{Access}

Access to the war-affected population in southern Sudan was complicated by the international community adhering to absolute sovereignty of Sudan and access depending on negotiations with the GoS. However, the operation was innovative in terms of its framework in regards to international humanitarian policy and conflict management, as it enabled to provide relief to areas controlled by a non-state actor in the midst of an intrastate conflict (Bradbury et al, 2000, p. 27). OLS began under the auspices of the UN with the consent of the GoS and after signing an agreement with the SPLA on opening of 'corridors of tranquillity' (also called 'corridors of peace' as they led to temporary cease-fires) in SPLA-held areas (Duffield, 1994, p. 7; Barltrop, 2011, p. 79), enabling safe delivery of humanitarian aid to SPLA-controlled areas by UNICEF (as the leading agency), the WFP and 35 NGOs (Barltrop, 2011, p. 75). This was the first time in history that the UN initiated an operation which was aimed at helping both sides of an intrastate conflict, particularly where one side of the conflict was the government of the country (Macrae et al, 1997, p. 224). During the Cold War, absolute state sovereignty and non-intervention were some of the main pillars of foreign policy. As the operation started before the end of the Cold War, Sudan's absolute sovereignty was still respected, and access to population in need of international relief depended on ambiguous and provisional ceding of sovereignty to the UN (Karim et al, 1996, p. 1). Failures of OLS have since led the international community to the inclusion of 'protection of civilians' in every UN mandate and later to the establishment of the Responsibility to Protect (R2P) norm. On the other hand, the presence of aid agencies in SPLA-held areas was seen by the GoS as support for the rebels and it exacerbated tensions between the two warring parties. It also 
gave the SPLA an international recognition and a hope for an independent future in South Sudan (Duffield, 2000, p. 179-180).

Negotiated access was typical for UN operations in the first years after the end of the Cold War (Duffield, 1994, p. 7). Although it was seen as a historical turning point in the aftermath of the Cold War that the UN was able to access vulnerable populations in an on-going conflict, previously only possible for the Red Cross (Duffield, 1994, p. 7), the operation was susceptible to political manipulation from the GoS. The consent of the GoS was central to the operation, and aid allocations to famine stricken areas were negotiated between the UN and the GoS on a weekly and monthly basis. As the GoS had the power to grant or deny access to aid convoys and air deliveries, it also had the power to control the movement of the population in Sudan, as in complex emergencies populations tend to migrate to places where aid is delivered (Shearer citing Keen, 2000, p. 190-191). In this case, negotiated access led to further displacement in Sudan.

Displacement of populations is one of the largest issues of contemporary crises, particularly the displacement within countries of origin. While the numbers of refugees decreased in the last few decades, the numbers of IDPs in developing countries started growing towards the end of the Cold War (Terry, 2002, p. 12), and have continue to grow ever since due to protracted crises and increased unwillingness of neighbouring countries to accept more refugees. Another reason for the growing numbers of IDPs was that aid was increasingly delivered directly to them, and camps were set up within their countries of origin rather than having to cross borders to refugee camps in neighbouring countries. At approximately five million, Sudanese IDPs were one of the largest IDP populations in the world during OLS. Many were pushed to the safer, northern part of the country (Duffield, 2002, p. 84). Also, a lot of southern Sudanese displaced by conflict settled in the transition zone between the North and the South. The area has been, however, characterised by constant tensions between Arab and African ethnic groups. Furthermore, most of the time it was not accessible for aid agencies due to GoS' restrictions (Duffield, 2000, 192-193).

Internal displacement is a major issue, as there is no special international legislative body responsible for IDPs (such as the UNHCR for refugees), and primarily, IDPs are the responsibility of their government (Duffield, 2000, 192-193). In times of intrastate conflicts, where one of the factors is ethnicity or religion and the government of this country is part of the conflict and it contributes to the abuses of a part of the population, this becomes 
problematic. Therefore, negotiations with the GoS were challenging, as the GoS did not want to abandon its strategy of denying food to SPLA-held areas and imposed frequent flight bans over SPLA-held areas in the South. Duffield views GoS imposed flight bans as one of the main causes of the second famine in Bahr El-Ghazal in 1998 (Duffield, 2000, p. 217). Also Barltrop believes that the second famine was caused mainly by a total flight ban over Bahr elGhazal imposed by GoS in January 1998 (Barltrop, 2011, p. 87). However, others suggested that another reason for the development of the famine was the adoption of the relief-todevelopment continuum (see above). Aid delivery by land was also difficult due to poor infrastructure in the country caused by decades of conflict. OLS ended in 2004. One year later, the GoS signed the Comprehensive Peace Agreement (CPA) with the SPLA, thus ending the Second Sudanese Civil War. Signing of the CPA also enabled better accessibility of the affected population in southern Sudan as the international community no longer needed to negotiate access with the GoS.

\subsection{Conclusion to Chapter 3}

As OLS was one of the first UN-led humanitarian operations, the international community had no experience in providing relief to a country in the midst of a civil war. After analysing humanitarian effectiveness of OLS through the application of the 2013 OCHA-proposed Elements of Effectiveness, it can be said that even though the operation was mostly lacking data and transparency, and therefore the analysis might not be completely accurate, OLS was not very successful in terms of humanitarian effectiveness. OLS failed in more than one regard. Undoubtedly, without UN intervention even more people would have died. However, successes on the micro-level cannot compensate for the range of mistakes on the macro-level. One of the biggest issues was negotiated access, as the GoS made it difficult for aid agencies to access affected civilian population in the South of the country. Furthermore, aid agencies, particularly subcontracted NGOs, had little or no previous experience in working in the midst of a conflict, and the UN failed to coordinate agencies who were working under its auspices. The framework of the operation did not include protection of civilians and aid workers tended to concentrate in safer areas, while the most vulnerable people were often neglected. Also, the operation was missing accountability mechanisms and diversion of relief was very common. As there was no precedent to follow, the framework of the operation was based on a Cold War natural disaster model which did not work in a complex emergency environment 
and did not take in account the underlying causes of the crisis. The UN failed to respond in a timely manner, and it lacked sufficient resources to cover necessary needs of the affected population. Another failure was the adoption of the relief-to-development continuum in the second half of the 1990s which contributed to the development of a second famine in southern Sudan. OLS was based on humanitarian principles and it was believed that humanitarian aid could help to resolve the conflict in Sudan. Therefore, the UN did not start searching for a political resolution for Sudan until the 2000s. The CPA, signed by the GoS and the SPLA in 2005, not only promised peace between the North and the South of Sudan, it also enabled better access to the war affected population. However, even though South Sudan became an independent country in 2011, fighting in both Sudan and South Sudan continues to this day and people are still in need of humanitarian aid. I am going to discuss these issues further in the Darfur context, particularly in relation to problems associated with lacking political action, problems with accessibility, lack of funding and lack coordination among humanitarian agencies. The following chapter uses OLS and its failures as a base for comparison to analyse whether lessons have been learned from the failures of OLS, if humanitarian effectiveness has improved since OLS, and what mechanisms the international community has set in place to make humanitarian aid more effective, if any. 


\section{Humanitarian Effectiveness in Darfur}

In this chapter, I will analyse humanitarian effectiveness during the most critical years of the Darfur crisis and compare it to OLS in order to demonstrate how little had changed in the humanitarian response to complex emergencies in the Sudanese context in the years between the launch of OLS and the outbreak of the Darfur crisis.

While peace talks between the North and the South were underway and OLS was coming to an end, another crisis developed in the former Sudan in 2003. The main actors in Darfur were the same as during OLS, the GoS and the SPLA, and the underlying causes of the Darfur crisis were also political (caused by ethnic and socio-economic differences within the society) and the crisis needed primarily a political solution (diplomatic and/or military). On the other hand, Darfur was also different in many regards. While the emergency during OLS was primarily caused by a famine which developed as a result of GoS strategy of denying food to the population in opposition-held areas in South Sudan, the crisis in Darfur was ultimately caused by ethnic violence and human rights abuses inflicted on the civilian population by GoS armed forces and affiliated militia groups. Therefore, Darfur has also been described as a human rights crisis and a crisis of protection.

Nonetheless, the crisis in Darfur between 2003 and 2005 has been described as one of the world's largest humanitarian catastrophes, resulting in the deaths of hundreds of thousands of innocent civilians. The international community, although not causing the tragedy, failed to intervene effectively and prevent ethnic killings and widespread suffering of millions of Darfurians. Ultimately, humanitarian effectiveness in Darfur was hindered by a lot of similar problems to those during OLS, ranging from GoS restrictions to lack of funding and mistakes of humanitarian actors. One would have thought that after the highly criticised failures of OLS, the international community would have been able to respond more effectively when the crisis broke out in Darfur. Unfortunately, the opposite is true as the initial response to the Darfur emergency was highly ineffective and inadequate.

This chapter will critically analyse humanitarian effectiveness during the Darfur crisis, particularly between 2003 and 2005, and compare it to humanitarian effectiveness of OLS using the OCHA Elements of Effectiveness framework applied in the previous chapter. By providing this comparison, I will illustrate how little changed in the humanitarian response in the 14 years between OLS and Darfur. The international community was more experienced in responding to complex emergencies when the crisis in Darfur broke out, not only in terms of 
humanitarian aid, but also in terms of addressing the political aspects of Sudan's crises and other complex emergencies in different parts the world, and should have been able to respond more effectively to the crisis in Darfur than it did in southern Sudan. While the humanitarian response was undoubtedly inadequate and mostly ineffective, it is even more striking that the UN did not address the political aspects of the crisis for several years, despite the fact that the warring parties involved in Darfur were the same as during OLS and the peace talks on South Sudan between the GoS and the SPLA were still on-going when the crisis in Darfur broke out.

Furthermore, today, almost three years after South Sudan gained independence and became the world's newest country, and after extensive experience from OLS and Darfur, the humanitarian community is again facing potential humanitarian catastrophes unfolding in both Sudan and South Sudan. The two countries have experienced renewed outbreaks of violence and rapid deterioration of the security and humanitarian situations. The former Sudan has been one of the largest recipients of humanitarian aid in the last few decades due to on-going conflict, underdevelopment and almost permanent humanitarian emergencies. At the same time, peacekeeping forces are still present in both countries. However, neither efforts of aid agencies, nor multilateral peacekeeping missions have been able to prevent the Sudanese and South Sudanese populations from re-living the struggles of the past. The former Sudan is one of the most challenging environments for the complexity of the problems and issues it has experienced in the last few decades on political, social, ethnic and economic levels, including conflict, the countries' diverse societies, displacement, and chronic poverty (Belgasmi, 2007, p. 243). As the challenges today are not much different from the previous humanitarian crises in the former Sudan, I maintain that it can be helpful to identify failures of the past in order to improve humanitarian effectiveness today. First, however, the context of the Darfur crisis will be laid out for a better understanding of the crisis.

\subsection{Darfur Context}

As OLS was coming to an end and peace talks towards the CPA between Khartoum and South Sudan were underway, the next complex emergency was developing in the western part of Sudan - Darfur. Even though Darfur was not included in OLS operations, as OLS did not cover the whole of Sudan, some humanitarian organisations were present in the Darfur region already since the 1980 s. Similarly to South Sudan, Darfur has a high percentage of 
African population which was inconvenient for the GoS. A conflict in Darfur developed in March 2003 due to tensions between the GoS and two opposition groups, the SPLA and the Justice and Equality Movement (JEM). The international community failed to protect civilians when armed GoS-affiliated militias, the Janjaweed, deliberately targeted the civilian population in Darfur which resulted in deaths of hundreds of thousands of people. The statistics vary but some sources speak about up to over 400,000 victims of the Darfur genocide, although the GoS claimed it was not more than 7,000 and the international community was only trying to discredit the regime by exaggerating the numbers (Minear, 2005, p. 78). The crisis also caused massive displacement, resulting in the 'world's largest humanitarian emergency' (Barltrop, 2011, p. 98) which still continues today. Furthermore, although some aid agencies were already present in Darfur before the outbreak of the crisis, they were not able to respond effectively to the fast unfolding crisis. Aid agencies cannot be ultimately blamed for the deaths resulting from the raiding of the Janjaweed militias. Darfur was undoubtedly a political crisis and it needed a political (diplomatic and possibly military) response. However, the effectiveness of the humanitarian response was very poor, particularly during the first two critical years of the Darfur crisis.

Humanitarian actors in Darfur agreed that the emergency was also a human rights crisis, as most deaths resulted from violence against the civilian population, not from hunger and disease like during OLS (Minear, 2005, p. 86). The Janjaweed militias, Arab militant forces supported by the GoS, were deliberately targeting ethnic Africans in order to orchestrate ethnic cleansing of the African population in Darfur. Therefore, the tragedy sparked a renewed debate about the protection of civilians in intrastate conflicts; it was even compared to the genocide in Rwanda (where the international community failed to protect ethnic Tutsis from the violence of Hutu militias which resulted in estimated one million of victims). However, opinions differed on the use of the term genocide in the case of Darfur. Minear notes that it had not been proven that the GoS had a genocidal intent and president Bashir was later 'only' accused from crimes against humanity (Minear, 2005, p. 87).

Particularly brutal and alarming was violence against women inflicted by the Janjaweed militias. Brutal sexual assaults against women gathering firewood around IDP camps were common. Also, the need for protection of children was voiced by a few agencies as abuses of children's human rights were happening everywhere in Darfur, ranging from attacks, physical and sexual abuse, abduction, as well as recruitment of child soldiers. Several agencies implemented programmes to improve the situation of affected children and to prevent abuses 
of their rights, including advocacy efforts, education, and violence prevention. These programmes may have improved the situation for some children, but they did only little to improve the overall situation, and children continued to be directly targeted. The lack of protection for vulnerable IDPs is, even today, a prevailing problem in Darfur and in other complex emergencies around the world, such as Syria. As mentioned in the previous chapter, no UN agency has a protection mandate for IDPs, although the numbers of IDPs continue to grow and they have outnumbered refugees (Minear, 2005, p. 88-89).

The Darfur crisis possibly contributed to the adoption of the R2P norm at the World Summit in 2005. However, the implementation of R2P in the form of a UN peacekeeping mission for Darfur failed in 2006 due to the inability to obtain consent from the GoS. It was not until July 2007 when the African Union-United Nations Hybrid Operation in Darfur (UNAMID) was established. Until then, only the African Union Peacekeeping Mission in Sudan (AMIS) was active in Darfur (since 2004), but it was not able to prevent the violence towards the civilian population (International Coalition for the Responsibility to Protect website). Ultimately, humanitarian aid was (as with OLS) the only means helping the war-affected population in Darfur. As relief workers were witnessing the violence and human rights abuses towards the civilian population on a daily basis, protection of civilians was perceived by humanitarian agencies as the main priority. Some agencies, such as CARE, aimed at adopting humanrights-based approaches in their response. However, the agency admitted that there was disagreement within the organisation about how to implement it (CARE, 2004, p. 3).

The situation in Darfur was further complicated by the on-going peace process between the North and the South of Sudan. International actors saw the North-South process as their priority, and addressing the Darfur crisis remained secondary in its first years. As mentioned above, this is a continuing problem today. Darfur has been forgotten, and one wonders why it has not been as important for the world as South Sudan or other parts of the world. While South Sudan is rich in natural resources, particularly oil (as mentioned in the previous chapter), Darfur does not have too much to offer. Although the lack of natural resources in Darfur could possibly be an explanation for the negligence of the international community in the first years of the crisis, it is only a speculation.

UN's Francis Deng stressed in 2004 that the only way how to achieve sustainable peace in Darfur is through effectively addressing the underlying causes of the conflict. Until the root causes are addressed, it is necessary to provide aid and protection to the population of Darfur 
(Deng in Minear, 2005, p. 98). Darfur highlights the problems stemming from 'new humanitarianism' and the increased politicisation of the humanitarian enterprise (Okeke, 2011, p. 8). However, neither political actors, nor humanitarian agencies wanted to compromise the long-desired peace between the North and the South. Therefore, while the North-South peace talks in Naivasha were progressing, the situation in Darfur was deteriorating, despite several ceasefire agreements which both sides of the conflict kept breaking. Similar to OLS, humanitarian aid remained the main response tool for the international community in the first years of the Darfur crisis, and reminiscent of OLS, the response of humanitarian actors was far from effective. The following chapters will critically analyse humanitarian effectiveness during the first years of the Darfur crisis, compared to OLS, using the OCHA Elements of Effectiveness framework.

\subsection{Performance}

The overall performance of humanitarian actors in Darfur still remains difficult to measure due to the sketchiness of data available. Humanitarian agencies aimed at fulfilling their objectives of saving lives and reducing suffering of the affected civilian population and undoubtedly contributed to the improvement of conditions and reduced suffering of many people. While during OLS, the inability of humanitarian agencies to respond effectively could have been excused by their inexperience in working in the midst of an armed conflict, the international community had already 14 years of experience in responding to complex emergencies in Sudan and in other parts of the world when the crisis in Darfur broke out.

In many respects, humanitarian actors did not learn their lessons from OLS and the majority of humanitarian work in Darfur was still provided on an ad hoc basis. For instance, the initial humanitarian response was far too slow, aid agencies' tactics for targeting were unsatisfactory, and diversion and wastage of relief was too high. The operation was fragmented and the international community failed to see the whole picture (Minear, 2005, p. 116). Similar to OLS, while there were some successes on the micro level, the operation as a whole failed to respond to the crisis effectively. Furthermore, international relief lifted the burden of responsibility for the population from the GoS (Barltrop, 2011, p. 101). As mentioned in the previous chapter, the primary responsibility lies with the government of a country. When the government is not able to protect its citizens or, as in the case of Darfur, is causing harm to its citizens, the international community takes over the responsibility of the 
government. Still, if a government or its associates commit violent crimes against the people in this country, the accountability for those crimes lies with those who committed them. Then, the international response to this primary violence is called secondary responsibility (Slim in Minear, 2005, p. 114). The secondary responsibility of the humanitarian community was to provide relief to those in need in an effective and accountable manner.

\subsection{Accountability}

While during OLS accountability to affected populations, the host government, donors and other humanitarian actors was almost non-existent, some accountability mechanisms had been in place in Darfur as a result of most agencies adhering to the Sphere Standards (see below in chapter 4.6. on 'Principles and Standards'). An improvement of humanitarian response is evident in there being no claims of humanitarian aid influencing or prolonging conflict in Darfur (and no one made this claim, unlike during OLS). Still, the international community did not prevent violence inflicted on the population of Darfur. Although humanitarian actors themselves cannot be held accountable for the violence as such, they should be held accountable for how effectively and efficiently they use their resources, and their work should also be transparent in order to build trust with donors, beneficiaries, and the host government.

In this sense, accountability was still quite a major problem in Darfur, particularly due to inefficient targeting which led to wastefulness of resources and possibly even contributed to aiding not only civilians but also some insurgents. In this regard, Barltrop gives an example of the WFP. In 2004, the WFP opted for risking 'inclusion errors' in order to distribute aid as soon as possible to the affected population in dire need of aid, rather than carry out a lengthy registration and verification process. Later, the WFP admitted that those errors accounted for over 40 per cent of aid distributed in some IDP camps which can be seen as unacceptable wastefulness of resources in an environment where funding is limited and many people are in need of relief. Furthermore, when the WFP decided to register beneficiaries a year later, the procedure was accompanied by many problems, such as distortion and violence from both the local population and IDPs (Barltrop, 2011, p. 98).

Inefficient targeting remained a major problem in Darfur even in late 2000s. Beneficiaries were still receiving aid based on registrations carried out in 2005 and on IDP status (as either a displaced person or someone affected by displacement) (Young and Maxwell in Barltrop, 
2011, p. 99). Furthermore, status was determined on a group basis, and traditional structures played a major role in food distribution as traditional leaders usually acted as coordinators with aid agencies (Maxwell et al, 2011, p. 538). As was outlined in the previous chapter, this had already been identified as a problem during OLS, as aid was often distributed according to kin and not based on need alone. Another way in which targeting was inefficient, was the categorization of beneficiaries on the nature and scope of their displacement, such as IDPs, returnees, and the resident community, and distributing relief on a group basis, instead of assessing the need individually (Minear, 2005, p. 93). The question then becomes, would it have been possible for agencies to evaluate the needs of each person individually with the scope of the crisis? Nonetheless, the crisis was so severe that almost everyone in Darfur was affected by it. Almost everyone was in need of relief and individual beneficiary categories were not that different.

However, aid distribution on a group basis was used by the WFP as a tool to reach as many people in need of relief as possible, and the quality of the programme was secondary until 2005. From 2006 onwards, the agency concentrated more on the improvements of quality of aid delivery. While the WFP only provided relief to IDP camps in the initial stages of intervention, later the agency extended its activities beyond camps. This extension of activities was based on the agency's assessment which showed that rural populations were also affected by food insecurity, sometimes even more than IDPs, as their access to relief was limited and their livelihoods had been disrupted by conflict, natural conditions, as well as by the strain put on them by hosting large numbers of IDPs (Belgasmi, 2007, p. 247). Only the EU office for Humanitarian Aid and Civil Protection (ECHO) notes that their relief distribution was based on need and not status and included the host population as well as IDPs in order to reduce gaps and tensions in rural areas (ECHO, 2006, p. 4).

Also problematic was the uneven distribution of relief and patchy presence of aid agencies in the vast area that Darfur is spread on, as well as uneven coverage of different areas of Darfur. It was difficult to cover almost 500,000 square kilometres (for comparison that is approximately the size of Spain or France, or twice the size of New Zealand), due to access restrictions, lack of funding, and poor infrastructure. Most of the relief was distributed in and around Darfur's state capitals, and there were tensions created by the competition for relief between IDPs and host communities (Broughton, 2006, p. 7). Even though accountability guidelines and standards existed and most aid agencies attempted to follow them, performance weaknesses remained largely unaddressed, as there are no formal mechanisms in 
place to hold aid agencies accountable for their mistakes, either collective or individual (Broughton, 2006, p. 7).

Insecurity posed another difficulty for aid agencies due to the lack of protection when delivering relief (at least until UNAMID was established in 2007). Not uncommon was diversion of aid by the SPLA and by the JEM, or the Janjaweed militias. Incidents included looting of relief convoys, hijacking of vehicles, kidnapping or even killing of relief workers, and attacks on aid organisations' premises, such as warehouses with relief stock. Insurgent groups also sometimes tried to manipulate aid deliveries in the areas of their control. Diversion of aid by the opposition forces was a tactic of war, similar to the GoS' food denial strategy during OLS (Barltrop, 2011, p. 95). The WFP noted that people in Sudan have had years of practice in manipulating humanitarian assets and have learned to adapt resources for their own purpose. It was also common for non-civilians to access relief through their family and community ties (WFP in Minear, 2005, p. 105-106). Apart from diversion, aid supplies later stockpiled in warehouses had been also destroyed by insurgent militias in order for them not to reach the intended beneficiaries (Arola, 2007, p. 33). Furthermore, after the International Criminal Court issued an arrest warrant against president Bashir in 2009 for his involvement in Darfur, the GoS expelled 13 NGOs out of Sudan. In the end, the disruption did not cause as much harm for the organisations' beneficiaries as anticipated, as the UN and its partner agencies took over the work of expelled agencies (Barltrop, 2011, p. 99, 207).

\subsection{Coordination}

In cases when the government is not willing or able to take responsibility for its citizens, it is perceived as crucial by the international community for an UN agency to take on the role of the principal coordinator in humanitarian response to a major complex emergency (Minear, 2005, p. 107). However, the UN failed to mobilize an appropriate response, as well as to take on the role of a coordinator. Coordination of the humanitarian response in Darfur was seen as problematic by some NGOs, such as CARE and MSF, at least in the beginning of the crisis. There was competition between individual UN agencies about who is going to be the lead agency which made inter-agency coordination even more complicated in an already difficult working environment (Baker, 2004, p. 7).

OCHA, established in the late 1990s, lacked coordination authority in Darfur over subcontracted NGOs and other UN agencies, such as the UNHCR. Furthermore, OCHA 
failed to assess the scope of the crisis and allocate resources according to the degree of need. Coordination was problematic on a number of levels: interagency coordination within the $\mathrm{UN}$, coordination between the UN and other agencies, and within different national branches of individual international NGOs. The UN-centricity of the system and inability of OCHA to coordinate the assessment of need led to major geographical and sectorial gaps (Minear, 2005, p. 107-108), particularly in relation to protection, camp management, and the provision of shelter for IDPs. This was due to a combination of reasons, including the lack of capacity and resources, individual mandates of aid agencies, as well as selectivity of agencies in undertaking activities (Broughton, 2006, p. 6). The majority of problems associated with the lack of coordination and communication between agencies very much resemble OLS where large areas remained unaided. A positive improvement, however, was that UNICEF took on the responsibility to coordinate some sectors of the overall response, including child protection, education, water and sanitation, nutrition, and parts of health (Minear, 2005, p. 108). This signalled the implementation of the cluster approach following the 2005 humanitarian reforms. Furthermore, UNICEF was the coordinating agency throughout OLS and therefore it was probably the most experienced actor active in the whole response, and it had more opportunity to learn from previous mistakes.

As mentioned above, protection of civilians was seen as a major problem in Darfur. The UN did not have a unified protection strategy, and the UNHCR itself proved unable to address IDP protection and camp management. In fact, the UNHCR was largely absent in Darfur, it only operated in refugee camps in neighbouring Chad. Therefore, the OCHA Humanitarian Coordinator identified some NGOs and UN agencies to step in and take charge of IDP camp management. Broughton sees camp management particularly critical in protection of IDPs (Broughton, 2006, p. 6). However, these actors mostly had no experience in camp coordination and management, and they did not know how to protect civilians. Furthermore, some agencies noted that relief sometimes contributed to increased violence, as IDP camps were targeted by insurgents after receiving aid. In 2005, there were some 39 different NGOs in charge of Darfurian IDP camps, and the quality of services differed from one camp to another. Minear claims that it is problematic that NGOs did not feel accountable to OCHA. Furthermore, while almost one and half million of IDPs lived in camps run by humanitarian agencies that were inexperienced in camp management, one quarter of camps containing some 600,000 IDPs had no coordinator at all. Later, due to the absence of the UNHCR, 
OCHA subcontracted IDP camp management in some parts of Darfur to the International Organisation for Migration (IOM) (Minear, 2005, p. 93-94, 107, 108).

\subsection{Contextualization}

The humanitarian community was far more experienced in responding to complex emergencies when the crisis in Darfur broke out than it was in 1989 when OLS was launched, as a result of the multitude of intrastate conflicts after the end of the Cold War and the international community having to respond to them. Although the international community failed to respond to the Darfur crisis in a timely and sufficient manner, it was aware of the underlying political causes of the conflict, as the warring parties in Darfur were the same as during OLS, although the focal point of conflict was further north this time. However, there was a difference in the main cause of the tension between southern Sudan and Darfur. In Darfur, the primary cause of violence was ethnic animosity rather than economic grievances. Nonetheless, even though the international community was aware of the root causes of the conflict, it failed to address them (Minear, 2005, p. 101). The reasons for this failed response are quite complex, but ultimately, the international community was afraid to put political pressure on the GoS in regard to Darfur, as it did not want to compromise the North-South peace talks. Additionally, it was preoccupied with responding to other crises in other parts of the world (this will be further explained in detail below in section 4.7.).

\subsection{Principles and Standards}

The overall context of humanitarian aid during the Darfur crisis was different to OLS, as the peace process between the North and the South was underway. As was previously mentioned, Darfur was never part of the OLS mandate. The structure of the Darfur operation was no longer bipartite like OLS. The conflict was primarily political. All the factors and motivations that sustained the Darfur crisis were inherently political (Barltrop, 2011, p. 101). Humanitarian aid maintained its neutrality as it was no longer perceived as a potential solution to the crisis, and it was no longer used for the advancement of political interests. Also, peace talks were led separately from the relief operation and aid had not been used as an incentive in peace negotiations. In contrast to OLS, no one claimed any potential influence of aid on conflict in Darfur. Aid agencies only responded to humanitarian needs of the 
affected population and relief did not divert attention from political causes of the conflict. However, similar to OLS, the GoS did not pay any attention to the needs and rights of civilians in Darfur, and the international community had to take over the responsibility of the population's wellbeing, removing the burden from the government. Therefore, although the international community separated conflict and peace resolution from relief, humanitarian aid assisted to domestic depoliticization of the crisis (Barltrop, 2011, p. 95-96).

However, Minear notes that even though the intention of the international community was to avoid mistakes from previous humanitarian crises and to keep humanitarian aid away from politics, relief provided in a political environment like Darfur will be inherently political. The aim for humanitarian actors was to minimize the political factor and adhere to core humanitarian principles, particularly neutrality, in order to gain access to affected populations. While there were again some successes on the micro-level, such as UNICEF's polio campaign enabled access to both GoS and SPLA-held areas, mostly, SPLA-controlled areas were inaccessible to humanitarian actors. Access mostly depended on political and military considerations of the GoS (more detail on access is provided in section 4.11.). Humanitarian actors had to be particularly careful in maintaining their neutrality in the eyes of the GoS, as peace talks on the North-South crisis were still on-going in Naivasha, Kenya. Furthermore, debates about genocide and the role of the US as Sudan's largest donor and the primary actor in to the global war against terrorism added to the highly sensitive political mix (Minear, 2005, p. 97-98).

While no claims of aid influencing conflict had been raised in Darfur, on-going violence had undoubtedly influenced the work of humanitarian agencies, particularly due to problems with accessibility and insecurity. As mentioned previously, lack of protection was a major issue. It complicated the work of humanitarian agencies and put at risk locals who cooperated with agencies on different awareness-raising programmes and training, such as on human rights and cultural awareness. While humanitarian actors were aware of the sensitivity of the situation, in general, NGOs tended to push boundaries with the GoS further than the UN (Minear, 2005, p. 103). Furthermore, as access to SPLA and JEM-held areas was limited (see below), relief was provided mainly only in GoS-controlled areas.

Whilst humanitarian actors wanted to follow humanitarian principles and did not want to exacerbate the conflict, humanitarian principles had been compromised (OCHA In Minear, 2005 , p. 104). The need for aid was the same on both sides of the conflict, ethnicity or 
political belief notwithstanding. However, the GoS denied humanitarian agencies access to affected populations which compromised the principle of humanity, the right of Darfurian civilians to receive aid. While the bias in favour of GoS-controlled areas was unintentional, the circumstances on the ground and GoS policies and travel restrictions constrained the majority of aid being provided in GoS areas of influence, while neglecting IDPs in opposition-held areas. Again, in contrast to UN agencies and their partners, some NGOs, such as Save the Children, did not adhere to GoS policies and UN Security Council (SC) regulations and managed to provide some relief to IDPs in areas with restricted access (UNICEF In Minear, 2005, p. 104). Also, impartiality had been compromised both during OLS and during the Darfur crisis. According to Young, the main focus of humanitarian agencies has been the African population and the needs of Arab communities have been at the bottom of the agenda, although they have also been affected by the crisis and needed humanitarian aid (Young et al in Minear, 2005, p. 105).

Humanitarian agencies expressed in their evaluations of their response to the Darfur crisis the need to improve their performance. The key to the improvement of performance was seen in adherence to professional standards and mechanisms, namely traditional humanitarian principles and other tools, such as the Sphere Standards. In contrast to OLS, where relief consisted primarily of food aid, the response to the Darfur emergency shows an improvement in terms of the Sphere Standards. As the conflict in Darfur disintegrated the local population from their livelihoods, the international community aimed at integrating a livelihood supporting and saving strategy in their response which would support people's own ability to provide for themselves (Minear, 2005, p. 94-95). However, the strategy posed a challenge for humanitarian agencies, as they were lacking experience in implementing such an approach. Moreover, this strategy brings back the memory of the relief-to-development continuum adopted during OLS which was perceived as the biggest mistake of the whole OLS operation (Minear, 2005, p. 97). However, in the case of OLS, a development-oriented approach was adopted too early, when people were still in dire need of relief and dying of hunger. As mentioned above, although the two crises had many similarities, the main difference between OLS and Darfur was that OLS was responding to famine while Darfur was mainly caused by ethnical violence which resulted not only in large-scale loss of life, but also widespread displacement and loss of livelihoods. Therefore, a livelihood-oriented approach seems like the right decision in case of Darfur. Nonetheless, the implementation of livelihood-supporting programmes was problematic as humanitarian agencies did not understand the livelihoods 
dynamics and traditional coping mechanisms interconnected with conflict and the war economy, further complicated by the diversity of the population (ranging from nomads, to agro-pastoralists and sedentary farmers) and the complex relationships between different groups. Therefore, the approach had only a narrow room for activity, and the implementation of livelihood programmes was limited as displacement continued even after the worst of violence had subsided (Young et al in Minear, 2005, p. 95-97). Nonetheless, Minear perceives this shift towards a livelihood-oriented approach as a positive one, as it promotes self-sustainability (Minear, 2005, p. 97).

Also, agencies expressed the importance of on-going evaluation of their work in order to adjust or correct their policies and planning (Minear, 2005, p. 113). However, OCHA, while appreciating adherence to standards and greater accountability compared to earlier crises, it stressed that standards are not objectives. Rather, OCHA framed them as targets. They are not absolutes but only indicators for humanitarian actors, and humanitarian actors also need to be accountable individually for their action and assess each situation separately (OCHA In Minear, 2005, p. 113). Similarly, ECHO noted that blindly following the Sphere Standards only leads to negative outcomes, as the strict use of the Standards is not suitable for Darfur circumstances. When applying the Standards, one must remain flexible and take into consideration the context and local norms (ECHO, 2006, p. 4-5).

\subsection{Relevance, Resilience and Preparedness}

The response of the international community to the crisis in Darfur had been described as systemic failure by Mark Bowden, the then head of OCHA Policy. He perceived the response as being characterised by lateness and inadequacy (Bowen in Stevenson, 2005, p. 7). This description is a variation of the 'too little too late' statement labelling OLS. The inadequacy of the response was caused by a combination of factors, such as the security situation on the ground, logistical challenges stemming from the vastness of the region and the lack of infrastructure, obstruction of aid deliveries by the GoS, the unwillingness of the international community to put pressure on the GoS due to on-going North-South peace talks, failure of the agencies already present in Darfur to recognise the nature and severity of the crisis, as well as competition for attention and resources with other crises in the world (Broughton, 2006, p. 3). According to Minear, there is a broad agreement between aid agencies that the humanitarian community took too long to respond, and that even after it geared up for a response, it never 
quite caught up with the emergency (Minear, 2005, p. 77). As the crisis continued and the numbers of people in need of humanitarian aid gradually increased, the response was continually characterised by under-delivery of assistance (Broughton, 2006, p. 3). Two years after the outbreak of the crisis, although the humanitarian community improved the situation of the affected population and mortality and morbidity data started decreasing, the then UN Under-Secretary-General Jan Egeland warned of a looming famine in 2005 as the situation deteriorated, despite the international presence (Minear, 2005, p. 84-85; Broughton, 2006, p. 3). Unlike OLS, a famine was avoided due to increased funding for Darfur later that year.

It is not possible to point to only one reason for the international community not responding in a timely and appropriate manner; there are many. The international community was not prepared for the crisis, and it took more than a year before the UN decided to intervene, despite reports of ethnic cleansing executed on the African population of Darfur by the Janjaweed militias (Minear, 2005, p. 79). By the time the UN SC passed the first resolution on Darfur in July 2004 and sent African Union peace monitors to observe the situation, the 'world's greatest humanitarian crisis' (as Jan Egeland called it) had unfolded. The reasons for such a development of the crisis were not only due to restricted access by the GoS, but also because the UN was afraid that if it would put pressure on the GoS, it would compromise the peace negotiations between the North and the South. Not only was South Sudan perceived as more important than Darfur; another reason for the inappropriateness of the response was that agencies concentrated on emergencies in other parts of the world. Darfur was not a priority for the international community. High profile emergencies, such as Iraq or Afghanistan received much more media attention and funding due to the perception that they were politically more important, although they were actually less acute from a humanitarian point of view (Minear, 2005, p. 81-82). Furthermore, South Sudan, Afghanistan, and Iraq are all rich in natural resources, while Darfur is poor.

Although some NGOs were already present in Darfur prior the outbreak of the crisis in March 2003, the UN and their partners were largely unprepared to respond to massive displacement and a subsequent humanitarian catastrophe. The crisis began after fighting broke out between the GoS and the SPLA and the JEM, and the situation further deteriorated after GoS-affiliated militias began targeting the civilian population in Darfur, causing widespread displacement. The numbers of both IDPs and refugees in neighbouring Chad were rising at a fast pace. There were half a million of IDPs in Darfur already by May 2003 and the numbers increase continued. Even though the international community was aware of 
the unfolding crisis, it took several months before it started paying any attention to Darfur, as the main focus was directed at South Sudan. NGOs already present in Darfur before the outbreak of the conflict concentrated mainly on development activities, and it also took them quite long to refocus and respond to the needs of the conflict-affected population. As in the case of OLS, several subsequent years of drought before the outbreak of the crisis contributed to worsening of food insecurity and heightened distress in the community (Minear, 2005, p. 78).

The Greater Darfur Initiative, a small-scale relief operation launched by the UN in September 2003 after signing of a peace agreement between the GoS and the SPLA (to which neither of the warring parties abided), was far from sufficient to respond to the needs of more than half a million Darfurians who were displaced by the end of the year (Barltrop, 2011, p. 97). Also, a UN country team was established in Khartoum to run the humanitarian operation, but Minear notes that their meetings lacked urgency towards the situation until December 2003, and a UN Disaster and Assessment Coordination team was not send to Darfur until February 2004. Also, UN leadership was missing in the overall response as northern Sudan was not a priority for the UN (Minear, 2005, p. 79). In addition, UN staff turnover in Khartoum was extremely high, and concerns had been raised by some agencies about the quality of UN staff assigned to coordinate the mission (Stevenson, 2005, p. 8). Not only did the UN as a whole respond in a slow manner, but individual UN agencies also failed to respond in a timely fashion, such as in the example of UNICEF, which Minear uses. The agency's response between March and October 2003 was small-scale and had little impact. Between November 2003 and April 2004, their programme dwindled due to lack of resources and security restraints. Finally, in May 2004, UNICEF recognised Darfur as an emergency and started mobilising resources to consolidate its activities from October 2004 onwards. The responses of other agencies involved were similarly inadequate, particularly at the beginning of the crisis (Minear, 2005, p. 79-80).

Another reason for the slow international response was related to the difficulties of aid agencies in assessing and monitoring of the magnitude of the crisis, caused by access restrictions (see below) and the vastness and remoteness of the region. Also, the situation was changing very quickly, as violence continued and generated more insecurity and displacement. Therefore, there was very little reliable information on how severe the situation really was, particularly in the beginning of the crisis when there were not that many observers on the ground (Minear, 2005, p. 81). 
Humanitarian needs in Darfur grew faster than anticipated; and so did the funding requirements. Therefore, relief programmes in Darfur struggled with funding shortages, particularly in the non-food sectors (Broughton, 2006, p. 3). Food aid was always a priority in complex emergencies but as mentioned in the previous section, in contrast to the aftermath of the Cold War and to OLS, aid actors recognised the importance of fulfilling all basic needs of affected populations in humanitarian emergencies, specifically apart from food aid, also water and sanitation, shelter, health care, and education. The donor community did not start contributing more funds until February 2004 (Minear, 2005, p. 82). The three largest donors, USAID (USA), ECHO (EU) and DFID (UK), did not initiate their support until the end of 2003, but the initial approved funds were far from sufficient. For instance, ECHO contributed $€ 2$ million in December 2003 (ECHO, 2006, p. 1). The initial UN estimated budget for Darfur was $\$ 23$ million, but as needs were growing, the budget estimate had grown to $\$ 171$ million by the end of 2003. The situation deteriorated even faster during the following year. By the end of 2004, Darfur produced 1.8 million IDPs and 2.5 million people in need of humanitarian aid; subsequently the needs assessment grew to \$621 million in 2005 which accounted for a total of 42 per cent of the whole Sudan aid appeal. Even though the conflict in Darfur attracted increased amounts of funding and aid for the whole of Sudan (including southern Sudan), aid organisations had still difficulties to cover the needs of the rapid growing numbers of conflict-affected civilians (Barltrop, 2011, p. 97).

Although the international response had improved from 2005 onwards compared to the first two years of the crisis, the needs in Darfur in the second half of the 2000s were still great. Over the next few years, the needs assessment for Darfur stabilized on $\$ 650$ million per year on average to cover humanitarian needs (Barltrop, 2011, p. 94, 96). Nonetheless, although Darfur was heavily publicised, the UN and its partners only received only on average approximately 70 per cent of the funding required each year in the second half of the $2000 \mathrm{~s}$ (Barltrop, 2011, p. 97). For instance, the WFP noted that in 2006 approximately 3.7 million people out of Darfur's population of six million received some sort of assistance. However, many people were still unable to access food, water, sanitation and other basic services, and the harvest was jeopardised due to insecurity stemming from continued fighting and unfavourable natural conditions. Humanitarian access remained problematic due to renewed violence (Belgasmi, 2007, p. 243)

After dismissing the Greater Darfur Initiative in 2004, a UN humanitarian response was launched. Funding also increased through so-called 'flash appeals', emergency appeals 
launched by humanitarian agencies to fund their growing emergency operations (Barltrop, 2011, p. 94). Although the UN Consolidated Appeal Process (CAP) was set in motion to raise more funds for Darfur, the process was slow and NGOs had to raise their own funds to cover their activities (Baker, 2004, p. 7). The lack of funding contributed to the slow and inadequate onset of the response. However, due to increased international media coverage and involvement of international movie stars, such as George Clooney and Angelina Jolie, the political and humanitarian crisis in Darfur attracted greater international attention. Subsequently, funding towards primary objectives of humanitarian aid increased. Due to increased funding, aid agencies did not have to be restricted to providing only food aid, and apart from saving lives, humanitarian aid activities in Darfur were increasingly aimed at strengthening human rights and humanitarian protection of the civilian population. Furthermore, aid agencies directed their efforts towards improving the quality, targeting, and cost effectiveness of humanitarian aid (Barltrop, 2011, p. 97).

Once a multilateral humanitarian response and the CAP were set in motion, the UN started providing the majority of relief goods and services, such as food aid, water and sanitation, shelter, health care, and protection to IDP camps across Darfur. This was done either directly, through cooperation with local and international NGOs, or through subcontracting to NGOs. However, throughout the first few years, not only were agencies struggling with funding shortages, but the UN was struggling with the lack of implementation partners (Broughton, 2006, p. 3). From 2007 onwards, after the UN finally commenced peacekeeping activities in Darfur and UNAMID replaced AMIS, the UN appeal increased to \$849 million in 2008 and $\$ 1,053$ million in 2009 (which included early recovery assistance in the previously solely humanitarian appeal) (Barltrop, 2011, p. 96). Furthermore, the UNAMID mandate included protection of civilians and safe provision of humanitarian aid. Therefore, aid agencies themselves no longer had to provide protection to IDPs after the commencement of UN peacekeeping activities in Darfur (which they should not have done in the first place).

Although Darfur attracted high levels of funding for the whole of Sudan, it still was not enough to cover all humanitarian needs in Darfur. Furthermore, when the UN finally mobilized a humanitarian response, they provided a biased portrait of their humanitarian impact (as noted in the previous chapter, aid agencies often modify their successes in order to please donors and attract more funding). The UN claimed in 2004 that they were able to aid 88 per cent of the affected population in Darfur. However, the data did not portray an actual need of the affected population but the 'accessible need'. This meant that the figures were 
based only on the population the international community was able to access. In other words, they provided relief to 88 per cent of the accessible population. Therefore, the actual numbers would have been much different and not as favourable for the UN. Moreover, the international community contended that the scope of the operation achieved by the end of the year was not sustainable in the long-term. Furthermore, the adequacy of the response was questioned as for instance, a whole IDP family would receive two blankets through the shelter package but international staff 'required' two blankets per person due to very cold over-night temperatures (Minear, 2005, p. 84).

On the other hand, some officials from the GoS as well as from the interim Government of South Sudan (GoSS) sometimes criticised the levels of aid for Darfur, as they felt as Darfur was taking away funding from other parts of the former Sudan and from long-term development activities in both Sudan and South Sudan. Nonetheless, due to increased oil production after 2005, the Sudanese economy experienced a sharp increase in revenues (between 2005 and 2009 national GDP grew by eight per cent on average) and both humanitarian and development aid represented only a small part of the economy (Barltrop, 2011, p. 100).

\subsection{Participation}

As in the case of OLS, participation in Darfur was poor. Particularly ownership and leadership from the GoS was lacking. Again, not only the government did not take responsibility for the population of Darfur, president Bashir was later accused of human rights abuses and crimes against humanity. Also, the GoS repeatedly denied humanitarian actors access into Darfur. Furthermore, not only did the GoS not prevent the Janjaweed militias from raiding and killing civilians, it is assumed that they supplied the Janjaweed with resources, such as military equipment. The absence of a strong government during a complex emergency creates a coordination challenge for the UN in the first place. OCHA also admitted that the work of UN humanitarian agencies in Darfur had been characterised by adhocracy due to obstacles to effective coordination caused by UN governance structures, funding sources, weak management, and institutional cultures (Minear, 2005, p. 109).

In the first years of the crisis in Darfur, participation of local structures, institutions and communities was mostly lacking, with a few exceptions, such as inclusion of male community leaders in IDP camps (Broughton, 2006, p. 8). For instance, while attention had 
been brought to the public about violence against women in and around IDP camps, engagement with women's leadership structures was missing (Minear, 2005, p. 92). Nor did the humanitarian community pay any attention to the impact of the crisis on different gender and age groups. The gender dimension had been incorrectly categorised as a reproductive health issue and not included in overall programming (Broughton, 2006, p. 8). A Food Relief Committee was later created in order to help to promote representation and participation of locals in the humanitarian aid processes (Maxwell et al, 2011, p. 538). It further helped to fill the void following the expulsion of 13 international NGOs in 2009. Today, 97 per cent of aid workers in Darfur are Sudanese and international organisations subcontract to local Sudanese agencies, as well as help them with training and support. Funding is distributed to local NGOs through the Common Humanitarian Fund (CHF) (OCHA, 1 Apr 2014).

International presence was, however, necessary for the establishment of relief programmes, and some agencies, such as MSF, noted that in the early stages of their intervention, they were lacking experienced and specialist expatriate staff to get their operation up and running. Some presence of foreign staff was also necessary for the protection of relief distribution. On the other hand, CARE noted that they would have benefited from heavier use of national staff as it would have minimised the operational cost and provide opportunities for employment (Minear, 2005, p. 110). According to OCHA, very little had been done in terms of inclusion of beneficiaries in the management matters in areas that concern them directly (OCHA in Minear, 2005, p. 114). Participation on the macro level was lacking, and there was widespread sense among beneficiaries that they were excluded from relief operations (Minear, 2005, p. 116). However, some agencies were more successful in promoting participation and ownership locally. CARE, for instance, set up participatory water and sanitation committees in IDP camps managed by the agency, where beneficiaries were included in planning and implementation of projects (CARE in Minear, 2005, p. 115).

\subsection{Capacity}

It is apparent from what has been said in the previous sections of this chapter that the overall capacity of the international community to respond to the Darfur crisis was insufficient. For most agencies, including the UN, Darfur was not a priority. In contrast to OLS, where the international community did not have the tools and knowledge to respond to major humanitarian emergencies, humanitarian actors in Darfur failed to mobilize a timely and 
effective response which strongly contrasted with responses to other complex emergencies that were underway at the same time. The agencies who did mobilize some staff and resources from the beginning of the crisis, such as the Red Cross and a few NGOs, were put under a lot of pressure, as the crisis was widespread and they were not able to cover the needs of the affected communities. Due to the shortages, humanitarian staff did not have the capacity to respond to burgeoning demands which often compromised their psychological welfare; the needs of local staff were particularly overlooked (Broughton, 2006, p. 4).

UN field presence was insufficient in both quality and quantity. The UN improved their field presence over time, but Broughton et al still felt that the UN did not do enough in Darfur, particularly in regards to human rights, security, and protection. While there were some individual or partial assessments of the security situation in Darfur, the lack of UN security officers in the field until 2005 meant that there was not enough security information on which aid actors could base their programming and operational planning decisions (Broughton, 2006, p. 5). Furthermore, political analysis undertaken by the UN was not shared with the humanitarian community. Nor did humanitarian agencies advance their capacity in undertaking political analysis. Social and livelihood analysis was also lacking. Another problem was the use of inexperienced staff without appropriate induction or training in the first stages of the response. Many humanitarian staff were neither familiar with the local situation, nor with the policies of their mother organisation. Using inexperienced and unknowledgeable staff put both the staff and aid beneficiaries at risk (Broughton et al, 2006, p. 7-8).

While a number of agencies were monitoring and evaluating their own activities in the first months and years of the crisis, their monitoring capacity decreased later on. Furthermore, common mechanisms for monitoring and evaluation were lacking, as was a unified interagency approach (Broughton, 2006, p. 7). Baker notes that while it was common for OCHA to prepare a standard assessment format for all agencies involved in order to unify information collection and to facilitate common reporting and coordination, OCHA did not provide one in Darfur which contributed to more chaos (Baker, 2004, p. 7). There was no attempt at an integrated cross-sectorial approach which led to too-narrowly oriented programming, often overlooking some factors of certain situations, and again leading to less effective responses. Effective programming would have required paying more attention to qualitative aspects of programming in order to meet the needs of aid recipients. However, the humanitarian community was concentrating on responding to immediate emergency needs 
and fulfilling short-term goals while neglecting the qualitative aspects and therefore hindering the effectiveness of their response (Broughton, 2006, p. 8).

As mentioned above, Darfur has often been described as a crisis of protection. In this regard, Minear particularly stresses the weakness of the UN system in response to protection and human rights abuses. While it took the international community more than a year to mobilize a humanitarian response, it took more than two years to address the lack of protection and lack of human rights field presence. On the other hand, some NGOs, such as Oxfam, while concentrating on advocacy, were failing to meet operational demands of their humanitarian programmes. Therefore, Minear raises concerns about whether the global humanitarian apparatus has the capacity to respond to such extreme emergencies, and also asks if combining humanitarian aid and protection activities does not undermine humanitarian effectiveness (Minear, 2005, p. 90-91). Humanitarian assistance cannot supplement political action. Just as it could not resolve the North-South conflict during OLS, it could not resolve the crisis in Darfur or prevent further civilian deaths resulting from violence. The Darfur crisis needed immediate attention and a political solution; but it was not forthcoming until 2007 when the UN SC authorised a peacekeeping mission.

As the priority of Darfur was protection as well as relief, the adoption of a human rights based approach by some agencies (see below 4.10.) was seen a step in the right direction by some scholars, such as Broughton. On the other hand, Broughton points out that humanitarian agencies did not know how to protect the affected population. The major issue was the lack of UN leadership in developing a protection strategy and problems associated with its implementation. The presence of a few thousand of humanitarian actors was not simply enough to protect millions of civilians in such a vast area. Some improvements were made over time in educating Darfurians about their rights, but women's and children's issues had not been monitored or addressed sufficiently and the community would have benefited from more diplomacy on behalf of women and children. While some general advocacy had been carried out (mostly by NGOs), a concerted advocacy approach was missing, and key UN actors remained silent on the issue (Broughton, 2006, p. 7-8). However, Broughton argues that implementing any protection and advocacy activities by the international community in Darfur was a very sensitive issue, particularly in regard to gender issues, such as sexual and gender-based violence, which made it even more complicated for aid actors (Broughton, 2006, p. 3). 


\subsection{Innovation}

In terms of innovation, it seems that not much had changed in the humanitarian response of the international community since OLS. The international community was not prepared for the crisis and humanitarian actors failed to adapt their response to the changing nature of the crisis. At first, it was problematic to access the affected population, and when GoS' restrictions eased, agencies failed to use the opportunity and to respond effectively. Minear suggests that Darfur is a prime example of the overall inadequacy of the humanitarian system in global terms (Minear, 2005, p. 86). In 2004, Sudan had the world's largest IDP populations in the world with approximately six million people. This number included both Darfur and southern Sudan. Internal displacement has been a major concern in the former Sudan (and in other complex emergencies around the world), and IDP camp management was problematic in Darfur, particularly due to the lack of coordination from the UN. The international community had made some improvements in regard to addressing overall IDP needs, compared to OLS where the focus was mainly on providing food aid. In Darfur, agencies were aware of the vulnerability of the IDP population, and from 2004 onwards they aimed to establish basic services in order to fulfil basic human rights for IDPs. Particular improvements were made in IDP camps health services. According to Minear, this positive indication only stresses the insufficiency of services in both South Sudan and Darfur before the outbreak of the crisis (Minear, 2005, p. 91-92).

While there is still an overall lack of data from the Darfur crisis, a positive improvement since OLS (where only one evaluation was carried out throughout the whole operation) was that a few agencies carried out real-time evaluations of their own work in the initial critical stages of the crisis. These included CARE, Oxfam, UNICEF, OCHA, and ECHO. Although real-time evaluations were helpful in identifying weaknesses and improving the work of each agency, follow-up evaluations would have been beneficial for future humanitarian action in Sudan and elsewhere. I repeat my earlier claim - on-going evaluation is the key to improving humanitarian effectiveness. Although the above-mentioned evaluations were an improvement, the international community has tended to provide evaluations of their work only through the most critical times of long-term emergencies in Sudan and South Sudan. It is striking that while Sudan and South Sudan remained two of the world's main recipients of humanitarian aid throughout the past decade, humanitarian actors have reflected on their 
work in both countries very little after 2005. Similarly, the crises have not received much attention in academia.

It has been mentioned in previous sections of this chapter that some agencies had combined their humanitarian efforts with advocacy, human rights and protection activities. There are differing views on the cooperation of humanitarian actors with other agencies, such as human rights actors. While some NGOs articulated their concerns about widespread human rights abuses by government forces and Janjaweed militias early on, other relief agencies (including the UN) were, however, still cautious in their advocacy efforts. They feared that putting pressure on the GoS could compromise their perceived neutrality, and it could mean denial of access, or even expulsion out of the country for the agency which in turn could be devastating for their beneficiaries. The GoS threatened to expulse Save the Children and Oxfam in 2004 after they advocated at the UN SC about human rights abuses in Darfur and, as mentioned above, 13 agencies were expelled in 2009. NGOs voicing their concerns in public could also face the denial or delay of visas and permits. Moreover, the UN was worried that Darfur could compromise the North-South peace talks (see above) (Minear, 2005, p. 90, 100). Nonetheless, in contrast to OLS, considering human rights and protection issues by humanitarian agencies signifies that, relief agencies were more thorough in analysing and considering the underlying causes of the conflict.

\subsection{Access}

Although the humanitarian operation in Darfur was not restricted by the notion of absolute sovereignty, access to the affected population in Darfur was still problematic. Minear perceives access restrictions as the most critical factor that limited the mobilization efforts (Minear, 2005, p. 81). The UN did not have to negotiate access with the GoS as they had to do during OLS, but the government still managed to find ways to control aid deliveries to rebel-held areas in Darfur, through visa and travel restrictions, work permits, import licenses for relief material, as well as flight bans. Those limitations undoubtedly affected the work of humanitarian agencies in terms of adequate and timely assistance (Barltrop, 2011, p. 95). Furthermore, access to rebel-held areas still had to be negotiated with the SPLA after the GoS had approved it (Minear, 2005, p. 116). Significantly, there was mostly no access to the affected population in rebel-held areas (Broughton, 2006, p. 3) who were, arguably, the most vulnerable. GoS restrictions had eased in July 2004 after signing one of the peace 
agreements, only to return in 2005. Easing and hardening of access restrictions has been a consistent feature of the Darfur crisis (Minear, 2005, p. 81). In fact, GoS has used the tactic of denying access since OLS, and still uses it today.

Aid deliveries to Darfur were characterised by insecurity and obstruction from all warring parties, as well as from different bandits and local militant groups. Maintaining security was very important as every time a crack in the security structure emerged, banditry and looting would take place (Belgasmi, 2007, p. 249). Barltrop sees the distance between Port Sudan and Darfur as problematic, as this main overland 'pipeline' for delivery is almost 2,000 kilometres long. Aid supplies were delivered by road or rail, and it took aid convoys approximately three weeks to cover the distance to Darfur due to poor infrastructure. This time frame and slow motion of the convoys gave all sides involved plenty of opportunities to block or divert aid from intended recipients (Barltrop, 2011, p. 97). Moreover, access was further complicated by weather conditions and the quality of roads. During the rainy season, aid supplies had to be airlifted as roads were unpaved and therefore inaccessible. This further increased the cost of aid delivery. Therefore, from 2005 onwards, the WFP started stockpiling aid supplies prior the rainy season which has proved very useful and cost effective (Belgasmi, 2007, p. 248).

\subsection{Beyond Darfur}

Even though Darfur received more attention and funding from 2005 onwards and the humanitarian situation improved, the international community never caught up with the emergency. Nor has a political solution been found for Darfur. Still, despite the lack of qualitative data to analyse effectiveness of relief provided in those years, the former Sudan remained one of the largest recipients of humanitarian aid in the last decade. Humanitarian aid, however, could not prevent recent re-escalation of conflicts in both Sudan and South Sudan, causing renewed humanitarian emergencies. It has been said multiple times throughout this thesis that humanitarian aid alone cannot resolve Sudan's and South Sudan's crises and there is an urgent need for political solutions in both countries. Although some improvements have been made in the way humanitarian aid is being provided today, humanitarian actors are still dealing with some of the same constraints and issues as they were 25 years ago when OLS was launched, such as problems with accessibility and funding. 
The recent events have shown that peace is very fragile in the former Sudan. Perhaps, not only the humanitarian sector needs to be reformed. It seems that the international community also needs to do politics differently. The international community was not able to apply R2P in Darfur (or in Syria which poses another example of an unresolved crisis where innocent people have been suffering for years). Perhaps the contemporary world needs a holistic approach to complex emergencies, possibly in the form of better cooperation and coordination between humanitarian and non-humanitarian actors? Perhaps the approach of the international community has to be more preventative, rather than reactive? The former Sudan has been in an on-going cycle of recurring conflict since the 1950s and the international community has periodically repeated the same mistakes in trying to resolve the conflict for the last 25 years. Although South Sudan seemed to have been on the right track before the outbreak of the crisis in 2013 as the overall situation had improved in terms of security and development, it did not need much to fall back into conflict six months ago which rapidly affected the whole country.

This thesis is not trying to find a solution to Sudan's and South Sudan's crises. I have analysed humanitarian effectiveness of Sudan and South Sudan crises, and shown that while humanitarian aid cannot be a solution for conflicts, it has often been the only means for the civilian population's survival. Humanitarian agencies cannot resolve complex emergencies. They can, nonetheless, save lives, alleviate suffering, and maintain human dignity of people stricken by civil war, in accordance with Elements of Effectiveness (or with an even better set of norms the 2016 WHS might come up with). The mechanisms, processes, and approaches to achieve primary objectives of humanitarian aid have not been very effective in past crises in the former Sudan. Humanitarian actors have been periodically repeating the same mistakes over and over again. While the improvement in humanitarian effectiveness was minimal between OLS and Darfur, humanitarian actors have since implemented reforms which are aimed at the improvement of humanitarian effectiveness, such as the cluster approach used today. The international community has also recognised that the way to improvement of humanitarian effectiveness is through monitoring and evaluation of relief operations and programmes, reflection on past mistakes, and learning from those mistakes. 


\section{Thesis Conclusion}

The humanitarian realm has changed significantly after the end of the Cold War due to profound changes in the world order. Complex emergencies, caused by emerging intrastate conflicts, generated a greater demand for humanitarian aid. Opening of international borders enabled relief agencies to access affected populations inside of their country of origin, and it brought new actors to the humanitarian realm. New humanitarianism has, however, been characterized by adhocracy, lack of coordination and accountability, as well as by lack of funding. Furthermore, humanitarian aid has often been the only response of the international community to a complex emergency when there would have been need for a political solution, addressing underlying causes of the crisis, to end a conflict. While in the first few years after the end of the Cold War, new humanitarianism was received positively, after several major failures, it started to be criticised for having negative effects on conflict, and later for being ineffective altogether. The international community today sees an evergrowing need for humanitarian aid in different parts of the world due to the growing number of complex emergencies and increased numbers of people in need of relief. It has also recognised the need for greater humanitarian effectiveness. Yet the international community still has not come to an agreement on how to achieve it. This thesis has analysed humanitarian effectiveness in the former Sudan using OCHA proposed Elements of Effectiveness as a framework in order to show that humanitarian operations have been repeatedly ineffective in the past.

The former Sudan has been one of the world's largest recipients of humanitarian aid since the end of the Cold War due to protracted conflict and on-going insecurity. Sudan and South Sudan remain some of the least developed countries in the world. The former Sudan was also one of the first countries to receive help from humanitarian actors after the end of the Cold War. Operation Lifeline Sudan was launched as the Cold War was ending, and it was unprecedented for the international community to intervene in the midst of a conflict where one of the insurgents was the government of the country. While OLS undeniably saved lives of many people affected by conflict and famine, it was also one of the greatest failures in terms of humanitarian effectiveness. Even though OLS performance was restricted by negotiating access with the GoS, the main reason for the ineffectiveness of humanitarian response was inexperience of humanitarian actors involved, as they never before worked in the midst of a conflict. Furthermore, OLS was characterized by periodical repetition of the 
same mistakes due to proliferation of aid workers. Accountability and transparency did not concern humanitarian actors very much in the first years after the end of the Cold War, and while there is an overall lack of data, diversion and manipulation of aid, uneven distribution, as well as lacking local ownership (on all levels) was very common during OLS. GoS ownership was particularly lacking. Contrarily, the GoS was blocking relief for civilian populations in the rebel-held areas, and government forces were directly targeting civilians. Some agencies set up community based projects after the adoption of the relief-todevelopment continuum, but they were largely unsuccessful as agencies tended to set them up in unstable areas. Insufficient local knowledge led humanitarian agencies to choose ineffective targeting strategies, and they failed to promote ownership of the local population. Furthermore, it was believed at the time that humanitarian relief itself could resolve the conflict.

OLS framework was derived from the 1980s natural disasters model which had proven ineffective in a complex emergency, as it did not regard the context of the crisis, the socioeconomic and political factors which caused the crisis in the first place. Therefore, aid negotiations mostly supplemented much needed diplomatic action. As the UN had to negotiate access to the affected population with the warring parties, the operation was susceptible to political manipulation by both the warring parties and international actors. Humanitarian principles were, therefore, often compromised, even though the OLS mandate stressed the importance of its neutrality. Nonetheless, while maintaining humanitarian principles during OLS was crucial for enabling access to affected populations, negotiated access was one of the main downfalls of the operation. By providing relief in SPLA-held areas, humanitarian agencies were often perceived by the GoS as supporting the rebels which led to more access restrictions.

Overall, OLS responded very late to the widespread famine, and it did not even cover basic needs of the affected population. A second famine developed in southern Sudan while OLS was still underway due to continued access restrictions and a premature adoption of the reliefto-development continuum. OLS adopted development strategies when the population was still malnourished and in need of basic food aid in order to survive. Furthermore, the UN was lacking sufficient capacity for the implementation of aid projects. While it subcontracted some projects to other agencies, particularly NGOs, it failed to act as a coordinator of the whole operation. There was also insufficient communication between individual humanitarian actors and projects often overlapped. Agencies tended to concentrate in safer 
areas, while the most vulnerable populations were often overlooked. OLS was characterized by proliferation of staff and resources, and mistakes were periodically repeated. Additionally, the operation did not include protection of civilians in its mandate. While lack of protection was a major problem during OLS, it became even a bigger issue in Darfur.

The crisis in Darfur started when OLS was coming to an end, while North-South peace negotiations were on-going. Darfur benefitted very little from the experience of OLS, and little improvement was made in the overall response to the Darfur crisis compared to OLS. Although some improvements were made in the institutional response of the humanitarian community, it was slow and reactive, and the same mistakes were repeated. Analysing effectiveness of the humanitarian response to the Darfur crisis is complicated by the continued lack of data available. While compared to OLS the number of evaluations provided by aid agencies themselves had increased, humanitarian effectiveness of the Darfur response has not been addressed much in academic literature. It is only now that the international community has started focusing on the need to address and improve humanitarian effectiveness, or rather ineffectiveness of humanitarian operations. The international community has finally recognised that the same mistakes are being periodically repeated in institutional responses to complex emergencies, and the key to improving humanitarian effectiveness is seen in developing a better set of standards for providing humanitarian aid, based on monitoring and evaluation of humanitarian programmes and projects and learning from past mistakes. While humanitarian effectiveness has still not been defined, there are discussions underway in the humanitarian community, which should conclude at the WHS in 2016. Using the Elements of Effectiveness framework, proposed for the WHS, has proven very helpful for this thesis in identifying gaps and shortcomings of past operations.

Despite humanitarian actors having 14 years of experience in Sudan and other complex emergencies in different parts of the world when the crisis in Darfur broke out, improvements in humanitarian effectiveness were relatively few compared to OLS. The UN and other agencies should have been able to respond more effectively. While agencies were not restrained by absolute sovereignty anymore, they should have been able to mobilize a timely and concerted response. Most of the shortcomings in Darfur are variations of OLS failures. The international community was not prepared for such a large-scale emergency, and the overall humanitarian response was very late, inadequate, and fragmented. Also, as the international community failed to address the Darfur crisis on a political level, including the lack of protection (at least until UNAMID was launched in 2007), aid was again the only tool 
helping the affected civilian population. Accountability had slightly improved in Darfur due to adherence of most agencies to the Sphere Standards, but the majority of targeting strategies were inefficient and wasteful. Diversion of aid by warring parties, and to a lesser degree by beneficiaries themselves, was common. Furthermore, programmes lacked transparency, and even the data available were sometimes biased. Due to a lack of cooperation between individual agencies and insufficient UN coordination capacity, most areas of the vast Darfur region were left unattended.

The overall capacity of the humanitarian response was poor, as Darfur was not a priority for international actors. Particularly notable was an insufficient UN presence. A major problem in Darfur was the lack of protection, as violence of Janjaweed militias was directed towards the civilian population itself. In contrast to OLS, the international community was already aware of the underlying causes of the conflict, but it again failed to address them, particularly because it did not want to compromise North-South peace negotiations. On the other hand, humanitarian aid maintained its neutrality and it was no longer perceived as influencing conflict. However, maintaining neutrality and impartiality did not help aid agencies to access all people in need. Access was yet a major limitation in Darfur. Aid agencies were still limited by GoS access restrictions. They were also limited by the lack of funding, particularly in the beginning of the crisis. Participation remained poor, especially on the state level, but it was also largely lacking on the local and community levels. The approach of some agencies to combine humanitarian action with advocacy efforts in order to address human rights abuses and the lack of protection in Darfur was an innovative move. However, most agencies were careful with expressing their opinions as the GoS was sensitive to pressure and threatened agencies with expulsion.

Ten years after the outbreak of the crisis in Darfur, the international community is again facing some of the same challenges in the former Sudan as it was during OLS and in Darfur, specifically regarding access to conflict-affected populations, and with insufficient funding. While the current situation in South Sudan has deteriorated rapidly in the last six months, and millions of people are affected by it, some parts of Sudan, including Darfur, have been in a state of emergency for much longer and the international community still has not found a solution for Sudan, or Darfur. There are as many people in Sudan today in need of humanitarian aid, as there are in South Sudan, but it seems that Darfur and other parts of Sudan are just not as important for the international community. The South Sudan crisis has been highly publicised and it appears that only now, when the international community has 
responded to the South Sudan crisis, Sudan's (Darfur's) crisis is being addressed as well. Now when funds are being raised for South Sudan, Sudan's needs have been also attended to.

Access to affected populations is again restricted in both countries by increased instability and insecurity, government restrictions, and natural conditions, and therefore is not determined only by the international community. Funding mechanisms are still insufficient, despite the implementation of new funding mechanisms since the 2005 Humanitarian Reforms. Lack of funding necessary for an effective humanitarian response has been one of the biggest problems for humanitarian actors in recent crises in both Sudan and South Sudan. While funding mechanisms, such as the Common Humanitarian Fund (CHF), have provided some funds in accordance with Sudan and South Sudan implementation plans for 2014 (which were however introduced before the outbreak of the South Sudan crisis), funding is beyond insufficient and humanitarian actors have been urging donors to provide more financial resources to cover the needs of millions of people affected in both countries. So far, OCHA has raised 38 per cent of the total appeal of US\$ 1.27 billion for South Sudan (as of 17 April 2014), but only 6.4 per cent of US\$ 995 million required funding for Sudan (as of 24 March 2014) (Reliefweb, 17 April 2014; UN Web TV, 25 Mar 2014; Reliefweb, 24 March 2014).

Darfur has become a forgotten crisis. Although the humanitarian situation has remained critical in the last few years, funding for Darfur has notably decreased after 2011, despite a 40 per cent increase in humanitarian needs in the past year. Perhaps it is not interesting enough for the international community anymore, as it is not as rich in natural resources as the South. Or it is simply because the worst humanitarian crisis was thought to be over and there have been other humanitarian emergencies in other parts of the world attracting attention of the international community. A political solution for Darfur has still not been found. Indeed, the security situation in Darfur has worsened in the past year, and recent reports show that today humanitarian needs are again on the rise, as the numbers of newly displaced people in Darfur today are the highest since the worst crisis ten years ago. While Darfur was still receiving relatively high amounts of humanitarian aid until 2011, humanitarian funding for the whole of Sudan decreased in the last few years. Today, Darfur is again in desperate need of relief due to deteriorated humanitarian situation, and the international community is facing problems associated with underfunding and accessibility (UN Web TV, 25 Mar 2014). 
The question is, if the international community could have predicted the current crises in Sudan and South Sudan and could have raised sufficient funds in advance? With so many humanitarian emergencies all around the world, there is a need for different and more flexible funding mechanisms. One would think that after such a long history of recurring humanitarian crises and long-standing foreign presence in both Sudan and South Sudan, the international community should be able to respond proactively and effectively to emerging crises. Furthermore, pooled funding mechanisms, such as the CHF, have proven to be ineffective in fast-onset emergencies, as fund allocation through the CHF happens only once a year and it is not flexible enough to respond to disasters. The UN has been raising additional funds through flash appeals and rapid response funds, such as the Central Emergency Response Fund (CERF), as well as non-UN agencies raising funds themselves. But it is still not enough. John Ging, OCHA's Operating Director, has addressed this issue as 'donor fatigue', as global humanitarian needs are growing every year, and so is the funding gap (Reliefweb, 17 April 2014).

On the other hand, some improvements have been made in monitoring, on-going evaluation, programming, coordination, and capacity. While there are still factors the humanitarian community cannot influence, tools that OCHA is using in the current response seem to have improved overall humanitarian effectiveness. In particular, coordination has improved since OLS and Darfur. Since implementing Humanitarian Reforms in 2005, OCHA has established a new system for humanitarian responses in complex emergencies and natural disasters. The 'cluster approach' has been implemented in the current South Sudan operation. It is based on division of labour between individual UN agencies and their partners. For instance, the WFP is responsible for food security and logistics, UNICEF for nutrition, WASH (water, sanitation and hygiene) and education, the WHO for health, the UNHCR for protection and emergency shelter, and the UNHCR together with IOM for camp coordination and management. Since the outbreak of the crisis, OCHA is monitoring and evaluating the overall response on an ongoing basis and has been publishing updates every three weeks since the outbreak of the crisis in December 2013, based on individual clusters. Each cluster is accountable to the Humanitarian Coordinator for South Sudan, appointed by the OCHA Humanitarian and Emergency Relief Coordinator. A similar approach has been recently also implemented in Darfur.

However, humanitarian effectiveness still depends on levels of access, donor support, as well as on the performance and accountability of humanitarian actors, and additionally on the 
inclusion of local structures, both governments and communities. Nonetheless, it is clear today that aid cannot be the solution to Sudan's and South Sudan's conflicts. Their crises are inherently political, stemming from economic and ethnic grievances, and aid alone cannot resolve them. Ging recently stressed that the key to improvement in the former Sudan is putting an end to the conflicts (Reliefweb, 17 April 2014). As during the OLS and Darfur crises, humanitarian actors today can only help people suffering from conflict to a certain extent. They cannot resolve political crises. There is always a need for a political solution which would address the underlying socio-economic causes of an intrastate conflict. While necessary to save lives, alleviate suffering and enable basic human rights to the civilian population in all complex emergencies, humanitarian aid needs to stay separate from political actions in order to be effective. Particularly in Sudan and South Sudan where the authorities are sensitive to any implications that relief activities could be associated with the opposition, humanitarian actors need to adhere to humanitarian principles. On the one hand, it is important for aid agencies to maintain their neutrality in order to be able to provide relief to people in need. On the other hand however, as Darfur has shown, humanitarian agencies often do not have the capacity to protect civilian populations. Protection, or the lack of, remains a major issue in the former Sudan.

It is difficult to analyse or predict overall humanitarian effectiveness of the international response to the present crises in Sudan and particularly South Sudan for the lack of available data. While OCHA has been monitoring and evaluating their response on an on-going basis, most agencies remain silent, except for their fundraising appeals. Also, the media mostly only interpret information received from OCHA. As stated in the first chapter of this thesis, monitoring and evaluation of humanitarian effectiveness is the key to its improvement. The lack of available data has, however, been the limitation of assessing overall humanitarian effectiveness in the former Sudan. While there is some qualitative and quantitative data on assistance provided during peak periods of humanitarian emergencies in the former Sudan (although not always reliable as it can be donor-biased), there is largely no qualitative data on relief activities between those peak periods. The humanitarian community, both agencies themselves as well as scholars, have tended to focus on humanitarian effectiveness in Sudan and South Sudan only during the worst crises (such as famine or genocide), even though both countries have been some of the largest recipients of humanitarian aid in the world in the last few decades also between the most vulnerable periods. While this thesis has shown that humanitarian effectiveness has not improved very much between the launch of OLS and the 
first years of the Darfur crisis, it has not been possible to assess if humanitarian effectiveness has improved during the last decade after the worst crisis in Darfur was over, due to the lack of available information.

While there are still some of the same limitations visible in the response to the current crises in the former Sudan, one could say that some aspects seem to have improved in the multilateral response, such as through the implementation of the cluster approach. Nonetheless, the overall international response today is too reactive, and there is a need for more prevention and preparedness to respond to potential crises in fragile environments, such as the former Sudan which is known for being prone to recurring conflict. The current crisis in South Sudan has shown how little it takes to throw the whole country back into conflict and destroy all the positive developments that have been achieved during the last decade. It is crucial that the international community addresses current gaps and weaknesses of humanitarian effectiveness in order to overcome the vicious circle of complex emergencies and humanitarian crises. First and foremost however, the international community needs to be able to resolve conflicts on a political level in order to find a way to lasting peace not only for Sudan and South Sudan, but also to other prolonged crises in other parts of the world.

In terms of improving humanitarian effectiveness, the international community needs to develop a better set of standards and policies for multilateral humanitarian response which should be respected by all humanitarian actors. While some learning has certainly taken place, there is definitely a need for better funding mechanisms corresponding to growing humanitarian needs in the developing world. I argue that the key to improving humanitarian effectiveness is on-going learning from past mistakes through monitoring and evaluation based on the OCHA proposed Elements of Effectiveness or similar. While the 2005 Reforms were definitely a positive step towards better humanitarian effectiveness, they were still not enough to respond to contemporary humanitarian crises. This is visible from the emerging shortcomings of the current relief operations in the former Sudan. The Elements of Effectiveness framework proved useful for identifying shortcomings of OLS and Darfur. Shortcomings of past and current humanitarian operations should be the starting point for the development of better humanitarian effectiveness mechanisms for future humanitarian operations, including the development of professional standards for humanitarian agencies and possibly even drawing of conclusions for agencies that do not adhere to these standards. At present, there are no repercussions for agencies that do not follow humanitarian principles or comply with humanitarian principles or the Sphere Standards. The upcoming World 
Humanitarian Summit could bring these necessary improvements of humanitarian standards and policies towards greater humanitarian effectiveness. 


\section{BIBLIOGRAPHY}

Anderson, Mary B., Do No Harm: How Aid can Support Peace - or War (Boulder: Lynne Rienner Publishers, 1999).

Arola, Sara Anne, Humanitarian Aid: Problems and Solutions, Thesis, Webster University London, 2007, http://search.proquest.com/docview/304335368 (accessed 10 Apr 2014).

Bailey, Sarah, and Harragin, Simon, Food Assistance, Reintegration and Dependency in Southern Sudan, ODI Humanitarian Policy Group, 2009, http://www.odi.org.uk/sites/odi.org.uk/files/odi-assets/publications-opinion-files/4847.pdf (accessed 1 Apr 2014).

Baker et al, CARE International's Humanitarian Response to the Darfur Crisis: Real-Time Evaluation, CARE, 2004, www.alnap.org/resource/3226 (accessed 1 April 2014).

Barltrop, Richard, Darfur and the International Community: The Challenges of Conflict Resolution in Sudan (London: I. B. Tauris \& Co Ltd, 2011).

Bauman, Peter, and Deng, David, Do No Harm in the Wake of Sudan's Comprehensive Peace Agreement, 2009, www.cdainc.com (accessed 28 May 2013).

Belgasmi, Daly, 'Humanitarian Action and Cooperation: Emergency Operations: Darfur, A Case Study', Refugee Survey Quarterly, Vol. 26, No. 4, 2007, http://rsq.oxfordjournals.org/content/26/4/243.full.pdf (accessed 1 Apr 2014).

Bradbury, Mark, Leader, Nicholas, and Mackintosh, Kate, The "Agreement on Ground Rules” in South Sudan, HPG Report 4, 2000, www.odi.org.uk (accessed 15 May 2013).

Broughton et al, Inter-agency Real-Time Evaluation of the Humanitarian Response to the Darfur Crisis, OCHA, 2006, https://docs.unocha.org/sites/.../RTE_DARFUR_Final_Report_14_Mar.pdf (accessed 1 Apr 2014).

Buchanan-Smith, Maggie, How the Sphere Project Came into Being: A Case Study of PolicyMaking in the Humanitarian Aid Sector and the Relative Influence of Research (London: ODI, 2003), http://kms1.isn.ethz.ch/serviceengine/Files/ISN/96043/ipublicationdocument_singledocument 14c69d200-0527-4088-8826-74bac7fc1aff/en/ODI+wp215.pdf (accessed 28 April 2014). 
CERF, Who We Are, http://www.unocha.org/cerf/about-us/who-we-are (accessed 11 Feb 2014).

DARA, HardTalk with Valerie Amos on Humanitarian Effectiveness, 15 Oct 2013, http://daraint.org/2013/10/16/4808/humanitarian-hardtalk-valerie-amos-aid-effectiveness/ (accessed 4 Feb 2014).

Davies et al, Coordinating Post-Conflict Aid in Southern Sudan, ODI Background Note, 2011, $\quad$ http://www.odi.org.uk/sites/odi.org.uk/files/odi-assets/publications-opinionfiles/7291.pdf (accessed 10 Apr 2014).

Duffield, Mark, 'Aid and Complicity: The Case of War-Displaced Southerners in the Northern Sudan', The Journal of Modern African Studies, Vol. 40, No. 1, 2002, pp. 83-104.

Duffield, Mark, 'Complex Emergencies and the Crisis of Developmentalism', Institute of Development Studies Bulletin, 1994, http://www.ids.ac.uk/files/dmfile/duffield254.pdf (accessed 28 Feb 2014).

Duffield, Mark, 'NGO Relief in War Zones: Towards an Analysis of the New Aid Paradigm', Third World Quarterly, Vol. 18, No. 3, 1997, pp. 527-542.

Duffield, Mark, Sudan: Unintended Consequences of Humanitarian Assistance - Field Evaluation Study (Dublin: Trinity College, 2000).

ECHO, Evaluation of DG ECHO Financed Operations relating to the Darfur Crisis, 2006, http://ec.europa.eu/echo/files/evaluation/2006/darfur_final.pdf (accessed 10 Apr 2014).

Efuk, Soforonio, 'Humanitarianism that Harms: A Critique of NGO Charity in Southern Sudan', Civil Wars, Vol. 3, No. 3, 2007, pp. 45-73.

Finnemore, Martha, and Sikkink, Kathryn, 'International Norm Dynamics and Political Change', International Organization, Vol. 52, No. 4, 2005, pp. 887-917.

Hofmann, Charles-Antoine, Measuring the Impact of Humanitarian Aid (London: ODI, 2004), http://www.alnap.org/resource/10518.aspx (accessed 28 April 2014).

Human Rights Watch, South Sudan: Ethnic Killings Spiralling, 23 April 2014, http://www.hrw.org/news/2014/04/23/south-sudan-ethnic-killings-spiraling (accessed 25 April 2014). 
IASC, About the Inter-Agency Standing Committee, http://www.humanitarianinfo.org/iasc/pageloader.aspx?page=content-about-default (accessed 5 Feb 2014).

IASC,

IASC

Principles

Transformative

Agenda,

http://www.humanitarianinfo.org/iasc/pageloader.aspx?page=content-template-

default\&bd=87 (accessed 5 February 2014).

ICRC, Geneva Convention relative to the Protection of Civilian Persons in Time of War, 1949, http://www.refworld.org/docid/3ae6b36d2.html (accessed 9 Jun 2013).

IFRC, The Seven Fundamental Principles, 1965, http://www.ifrc.org/en/publications-andreports/code-of-conduct/ (accessed 12 Jun 2013).

IFRC, World Disaster Report 2003, 2003, http://www.ifrc.org/Global/Publications/disasters/WDR/43800-WDR2003_En.pdf (accessed 28 April 2014).

International Coalition for the Responsibility to Protect, Crisis in Darfur, http://www.responsibilitytoprotect.org/index.php/crises/crisis-in-darfur $\quad$ (accessed $7 \mathrm{Apr}$ 2014).

IRIN News, Worsening Food Crisis in South Sudan's Swamplands, 3 March 2014, http://www.irinnews.org/report/99735/worsening-food-crisis-in-south-sudan-s-swamplands (accessed 5 March 2014).

Karim, Ataul et al, OLS Operation Lifeline Sudan: A Review (Juba: UNICEF, 1996), http://www.cf-hst.net/unicef-temp/Doc-Repository/Sudan-OLS-elec.html (accessed 6 March 2014).

Keen, David, 'The Functions of Famine in South-western Sudan: Implications of Relief', In: Macrae, Joanna, and Zwi, Anthony, eds., War and Hunger: Rethinking International Responses to Complex Emergencies (London: Zed Books, 1994).

Kopinak, Janice K., 'Humanitarian Aid: Are Effectiveness and Sustainability Impossible Dreams?', The Journal of Humanitarian Assistance, 2013, http://sites.tufts.edu/jha/archives/1935 (accessed 9 Jun 2013). 
Levine, Ian, Promoting Humanitarian Principles: The Southern Sudan Experience (London: ODI, 1997),

http://kms1.isn.ethz.ch/serviceengine/Files/ISN/97740/ipublicationdocument_singledocument 1454517B4-2DC5-44FB-AC20-A79854EB62ED/en/networkpaper021.pdf (accessed 28 May 2013).

Macrae, Joanna et al, 'Conflict, the Continuum and Chronic Emergencies: A Critical Analysis of the Scope for Linking Relief, Rehabilitation and Development Planning in Sudan', Disasters, Vol. 21, No. 3, 1997, pp. 223-243.

Marriage, Zoë, Challenging Aid in Africa (New York: Palgrave Macmillan, 2006).

Maxwell, Daniel et al, 'Targeting and Distribution in Complex Emergencies: Participatory Management of Humanitarian Food Assistance', Food Policy, Vol. 36, Issue 4, August 2011, pp.

$535-543$,

http://www.sciencedirect.com.helicon.vuw.ac.nz/science/article/pii/S0306919211000492\# (accessed 4 Apr 2014).

Minear, Larry, 'Lessons Learned: The Darfur Experience', In: ALNAP Review of Humanitarian Action in 2004, ALNAP, 2005, www.alnap.org/pool/files/alnap-chapter3-rha2006.pdf (accessed 27 Mar 2014).

OCHA, Brainstorming Workshop with Member States on Humanitarian Effectiveness, 7 May 2013 ,

http://www.regierung.li/fileadmin/dateien/botschaften/ny_dokumente/Workshop_on_Humani tarian_Effectiveness.pdf (accesses 14 Feb 2014).

OCHA, Consultative Workshop Humanitarian Effectiveness: Meeting Summary, 21 March 2013, $\quad$ https://docs.unocha.org/sites/dms/Documents/Meeting\%20Report\%20\%20Humanitarian\%20Effectiveness\%20Consultative\%20Workshop\%20\%2021\%20March\%202013.pdf (accessed 4 Feb 2014).

OCHA, Inter-Agency Real-Time Evaluation of the Humanitarian Response to the Darfur Crisis, https://ochanet.unocha.org/p/Documents/RTE_DARFUR_Final_Report_14_Mar.pdf (accessed 11 Feb 2014). 
OCHA, OCHA on Message: Humanitarian Principles, April 2010, https://ochanet.unocha.org/p/Documents/OOM_HumPrinciple_English.pdf (accessed 6 Feb 2014).

OCHA, South Sudan: Fear of Food Crisis in the World's Youngest Nation, April 2014, http://www.unocha.org/south-sudan/top-stories/south-sudan-fear-food-crisisworld\%E2\%80\%99s-youngest-nation (accessed 23 April 2014).

OCHA, Sudan: The Critical Role of National Humanitarian Organizations in Darfur, 1 April 2014, http://www.unocha.org/top-stories/all-stories/sudan-critical-role-national-humanitarianorganizations-darfur (accessed 4 Apr 2014).

OCHA, Sudan: 5 Facts about the Deepening Crisis in Darfur, 22 April 2014, http://www.unocha.org/media-centre/media-resources/multimedia-products/photogallery/sudan-5-facts-about-deepening-crisis (accessed 23 April 2014).

OCHA, Sudan/South Sudan: “Ordinary People Asked Us to Raise Our Voices”, 26 March 2014, $\quad$ http://www.unocha.org/top-stories/all-stories/sudansouth-sudan\%E2\%80\%9Cordinary-people-asked-us-raise-our-voices\%E2\%80\%9D (accessed 28 March 2014).

OECD, Glossary of Statistical Terms: Effectiveness, http://stats.oecd.org/glossary/detail.asp?ID=4775 (accessed 14 Feb 2014).

OECD, The Paris Declaration on Aid Effectiveness, 2005, http://www.oecd.org/development/effectiveness/34428351.pdf (accessed 6 Feb 2014).

OECD/DAC, Guidance for Evaluating Humanitarian Assistance in Complex Emergencies, 1999, http://www.oecd.org/dac/evaluation/2667294.pdf (accessed 4 Feb 2014).

Okeke, Jide, Why Humanitarian Aid in Darfur is not a Practice of the Responsibility to Protect (Uppsala: Nordiska Afrikainstitutet, 2011).

Polman, Linda, War Games: The Story of Aid and War in Modern Times (London: Viking, 2010).

Poole, Lydia, and Primrose, John, 'Southern Sudan: Funding According to Need', Global Humanitarian Assistance Briefing 2010, 
http://www.operationspaix.net/DATA/DOCUMENT/4490 v Southern_Sudan_Funding_A ccording_to_Need.pdf (accessed 17 Jul 2013).

Reliefweb, Darfur: New Displacement - First Quarter 2014, Situation Report No. 1, OCHA, 24 March

2014 ,

http://reliefweb.int/sites/reliefweb.int/files/resources/Darfur\%20New\%20displacement\%20\%20first\%20quarter\%202014\%20situation\%20report\%20No.\%201.pdf (accessed 23 April 2014).

Reliefweb, Darfur: New Humanitarian Needs and Aid Delivery Fact Sheet, OCHA, 14 April 2014 ,

http://reliefweb.int/sites/reliefweb.int/files/resources/Darfur_New_Humanitarian_Needs_and _Aid_Delivery_Fact_Sheet_-_14_April_2014.pdf (accessed 23 April 2014).

Reliefweb, South Sudan Crisis Response Plan: January to June 2014, OCHA, 3 February 2014 ,

http://reliefweb.int/sites/reliefweb.int/files/resources/South\%20Sudan\%20Crisis\%20Respons e\%20Plan_January\%20to\%20June\%202014\%20\%281\%29.pdf (accessed 14 Feb 2014).

Reliefweb, South Sudan Crisis Situation Report, Report No 32, 17 April 2014, http://reliefweb.int/sites/reliefweb.int/files/resources/South_Sudan_crisis_sitrep_32_as_of_17 _April_0.pdf (accessed 23 April 2014).

Rhodes, Tom, 'Famine Politics and the Cycle of Relief Failure in Sudan's Civil War: A Case Study of the OLS Relief Operation in the Bahr-el-Ghazal Famine, 1998', Global Politics Network, 2002, http://globalpolitics.de/essays/Tom_Rhodes.pdf (accessed 28 May 2013).

Riddell, Roger C., Does Foreign Aid Really Work? (New York: Oxford University Press, 2007).

Shearer, David, 'Aiding or Abetting? Humanitarian Aid and Its Economic Role in Civil War' In: Berdal, Mats, and Malone, David M., Greed and Grievance: Economic Agendas in Civil Wars (Boulder: Lynne Rienner, 2000), pp.189-203.

Slim, Hugo, 'Dithering over Darfur? A Preliminary Review of the International Response', International Affairs, Vol. 80, No. 5, 2004, pp. 811-828. 
Stevenson, Frances, Darfur 2004: A Review of MSF-Holland's Responsiveness and Strategic Choices, 2005, http://alnap.org/pool/files/erd-3291-full.pdf (accessed 6 Apr 2014).

Terry, Fiona, Condemned to Repeat? The Paradox of Humanitarian Action (Ithaca: Cornell University Press, 2002).

The SPHERE Project, Humanitarian Charter and Minimum Standards in Disaster Response, 2000, http://www.ifrc.org/PageFiles/95530/The-Sphere-Project-Handbook-20111.pdf (accessed 7 Apr 2014).

UN, The Secretary-General's Five-Year Action Agenda, 25 January 2012, http://www.un.org/sg/priorities/sg_agenda_2012.pdf (accessed 27 May 2014).

UN, UNAMID African Union/United Nations Hybrid Operation in Darfur, http://www.un.org/en/peacekeeping/missions/unamid/index.shtml (accessed 8 Apr 2014).

UN Radio, African Union-UN Mission in Darfur to Revise its Strategic Focus, 9 Apr 2014, http://www.unmultimedia.org/radio/english/2014/04/african-union-union-mission-in-darfurto-revise-its-strategic-focus/?utm_source=UN+Radio\&utm_medium=facebook $($ accessed 10 Apr 2014).

UN General Assembly, Resolution 46/182 Strengthening of the Coordination of Humanitarian Emergency Assistance of the United Nations, 19 Dec 1991, http://www.un.org/documents/ga/res/46/a46r182.htm (accessed 4 Feb 2014).

UN SC, Security Council Resolution $1769 \quad$ (2007), 2007 http://www.un.org/en/ga/search/view_doc.asp?symbol=S/RES/1769(2007) (accessed 8 Apr 2014).

UN Web TV, John Ging (OCHA) and Yasmin Haque (UNICEF) on South Sudan - Press Conference, 25 Mar 2014, http://webtv.un.org/watch/john-ging-ocha-and-yasmin-haqueunicef-on-south-sudan-press-conference/3390570687001/ (accessed 26 Mar 2014).

Van Voorhis, Bruce, 'Food as a Weapon of Peace: Operation Lifeline Sudan', Africa Today, Vol. 36, No. 3/4, 1989, pp. 29-42. 


\section{Annex 1 - Elements of Effectiveness}

One point that came out of the discussion was the consensus that humanitarian effectiveness could not be limited to just spending and fiscal accountability. Instead it had to be embedded in the overall economic, political and security context and had a strong operational aspect. Some of the elements that were identified as core issues that need to be considered as part of the effectiveness agenda are:

1. Performance - Do humanitarian actors meet core expectations for their activities? Is humanitarian work done according to clear professional standards? What is the role of certification for humanitarian organizations?

- Professionalization

- $\quad$ Certification

2. Accountability - Are there mechanisms and process set up to ensure that humanitarian action is accountable to affected populations, host governments, donors and other humanitarian organizations. Is humanitarian action transparent? Is there trust between humanitarians and other actors? Are there clear frameworks for analysing and managing risk, but which still allow flexibility of action in difficult and complex circumstances?

- $\quad$ Transparency

- $\quad$ Trust building

- $\quad$ Risk management

3. Coordination - Is humanitarian action coordinated at all levels - between international and national actors, within national systems, and with local level actors? Do Governments have the capacity needed to lead coordination efforts in all appropriate situations?

- International

- National

- Local

4. Contextualization - Is the approach being used appropriate to the context? Do humanitarians have clearly defined methodologies and approaches to respond to different types of contexts?

- $\quad$ Natural disaster or hazard

- $\quad$ Conflict

- Vulnerability context

5. Principles and Standards - Is humanitarian action grounded in the core principles? Are there clear professional and technical standards for operationalizing those principles? Are there ethical frameworks to monitor adherence to principles?

- $\quad$ Core humanitarian principles

- Common standards (SPHERE, HAP, etc.)

- $\quad$ Ethical frameworks 
6. Relevance - Are the aid and services provided appropriate to the context and the community? Was the aid delivered in a timely way when it was truly needed? Did it really suffice to relieve human suffering and reduce humanitarian needs?

- $\quad$ Timeliness

- $\quad$ Appropriateness

- Adequacy

7. Participation - Is humanitarian action fully inclusive of all relevant groups? Is there clear ownership and leadership by governments and affected populations?

- $\quad$ Ownership by governments and affected populations

- Inclusivity

8. Capacity - Do governments and international humanitarian actors have the systems and tools to deliver needed assistance? Are we fully utilizing local resources and capacities? Is there sufficient capacity to do strategic planning and coordination? What are the opportunities for technological advances?

- $\quad$ Systems and tools

- Planning and coordination

- Local resources

- Technology

9. Resilience and preparedness - Are humanitarian organizations engaged before a crisis in building preparedness? Do humanitarian interventions also help to address root causes of vulnerability? Are humanitarians working in a coordinated way with development actors?

- $\quad$ Resilience

- Preparedness

- $\quad$ DRR

- $\quad$ Risk and Vulnerability Management

10. Innovation - Are humanitarian actors exchanging best practices and identifying new opportunities to change the way they work? Is information flowing and being captured in a way that allows for improvement in the system? Is the humanitarian system adapting to the rapid transformations in society and technology?

- Innovation to capitalize on opportunities in data, information and communication:

- Innovation to support accountability challenges:

- Innovation to promote partnership:

- Innovation to better understand markets and market mechanisms:

- Innovation to solve difficult operational obstacles

11. Access - Are humanitarian actors able to reach people to provide help? Are there systems in place to ensure that those in need can access needed support? 